\title{
Experimental Study of Centrifugal Compressor Vaneless Diffuser Width
}

Ahti Jaatinen-Värri ${ }^{1}$, Pekka Röyttä ${ }^{1}$, Teemu Turunen-Saaresti ${ }^{1}$ and Aki Grönman ${ }^{1}$

Institute of Energy, Lappeenranta University of Technology, P.O. Box 20, FI-53851 Lappeenranta, Finland

Abstract

Seven different vaneless diffuser designs for a centrifugal compressor, varying only in diffuser width, were studied experimentally. The studied diffuser widths versus impeller exit width were 1.0, 0.903, 0.854 , and 0.806 . Three of the narrowed diffusers had the width reduced from the hub and shroud divided evenly, and the three others had the width reduced only from the shroud. The total and static pressures, the total temperature and the flow angles at the diffuser inlet and outlet were measured at the design rotational speed with three different mass flows. The impeller and diffuser performance was studied along with the axial distributions of flow angles and velocities in the diffuser. The results revealed that the pinch improved the compressor stage and impeller performance but deteriorated the diffuser performance. The pinch clearly decreased the secondary flow region present near the shroud. The pinch implemented in the shroud is more beneficial than pinch divided between the hub and the shroud. In order to obtain the beneficial effects of pinch, the pinch should be sufficient. However, excessive pinch deteriorates the compressor performance.

Keywords: centrifugal compressor; diffuser width; efficiency; flow field; vaneless diffuser

\section{Introduction}

Pressurising gases consume a lot of energy in many processes. Centrifugal compressors offer a highefficiency, light-weight, and relatively cheap way to pressurise gases, and they have replaced displacement compressors in many applications. Centrifugal compressors are widely used e. g. in combustion engine turbochargers, aviation, refrigeration processes, oil and gas industry, and waste 
water treatment. Centrifugal compressors are used in small gas turbines and they can be used in aerospace air-conditioning systems, as well. Therefore, improving the efficiency of centrifugal compressors can lead to significant energy savings. As the overall life-cycle cost should be the decision criterion for anyone who is investing in a compressor, inexpensive methods to increase the efficiency are the most likely to be taken into use by the manufacturers.

This paper focuses on vaneless diffusers. They are less efficient at the design operating point than their vaned counterparts, but they are cheaper to manufacture and offer a wider operating range. Even though the pinch, meaning here contracting of the flow area after the impeller by reducing the diffuser width, is commonly used design practice, the effects on the compressor performance are not yet completely understood.

In an early work by Senoo [1], the correlation between the ratio of the diffuser width to the radius at the diffuser inlet, $b_{2} / r_{2}$, and the critical flow angle was studied. The critical flow angle describes how tangential the flow can be at the diffuser inlet before the diffuser stalls. It was found that the smaller the $b_{2} / r_{2}$, the more tangential the flow entering the diffuser could be. Also the influence of the outlet/inlet radius ratio, $r_{2} / r_{3}$, was studied, and the critical flow angle was more tangential with the smaller radius ratio. Van den Braembussche et al. have reported similar results [2], and similar results have been found for centrifugal fans as well [3]. Based on this the diffuser width obviously has an effect on the stall inception. Engeda tested [4] two vaneless diffusers with one being narrower than the other, and the narrower one showed better surge margin at all tested speeds.

Different vaneless diffuser geometries were studied by Ludtke [5]. The studied diffusers were a parallel wall, highly tapered, constant area and parallel wall with width reduced by $47 \%$. The reduced width led to lower choke and surge limits of the compressor. The reduced width i.e. pinched diffuser 
also led to a lower overall efficiency of the compressor stage and to a lower mass flow at peak efficiency.

Ferrara et al. $[6,7]$ tested three geometries with large pinches and varied the diffuser length. The diffuser widths, $b / b_{2}$, were $0.64,0.38$, and 0.30 . No comparison to unpinched geometry was made. It was found that the stage efficiency decreased with increase in pinch and that the flow could be more tangential with increased pinch. The same diffusers were also tested with different impellers [8]. It was found that the trends were similar. Three different pinch shapes were tested. No difference in either efficiency or operation range between the shapes was found. The three papers also showed increase in the compressor working range with the reduction in the diffuser width, and the range increase was due to the stall inception shifting towards lower mass flows. The pinch shape was also found to have no effect by Tang [9].

The pinches used in the above-mentioned studies were quite large. Pinch, if moderate, can improve the compressor efficiency [10,11,12], and more importantly the pinch improves the impeller efficiency $[11,12]$. However, the root cause for the improvement remains unexplained.

Usually the pinch is used to have a larger safe operating margin between the peak efficiency operating point and stall/surge, as the stall inception shifts towards lower mass flows when the diffuser width is reduced. In this work the aim is to find out what the width reduction does in the design operating point.

In order to find out what causes this increase in the efficiency, detailed flow field measurements were made on seven different vaneless diffuser designs varying only by their width. The test bench, the test procedure and the results are presented in this paper. Conclusions on the results are also presented along with recommendations for the design engineers. 
The most important findings of the study were that implementing pinch decreases the secondary flow present near the shroud at the impeller outlet. This may be due to decreased tip clearance effects. In addition, shroud pinch is more beneficial than if the pinch is divided between the shroud and the hub.

\section{Measurements}

\subsection{Measured designs}

Six pinched geometries and one unpinched one were studied experimentally. The six pinched diffusers included three with shroud pinch and three with hub and shroud pinches. The diffuser width was varied from $b / b_{2}=1.00$ to 0.806 . The diffuser height was constant over the diffuser length. The pinch began at the constant radius ratio $r_{2} / r_{2}=1.01$ in all pinched geometries. The ratio of the diffuser exit and impeller exit radii was constant 1.68 for all designs. A summary of the studied configurations is shown in Table 1. The pinch shape is a straight wall perpendicular to the shroud wall combined with a rounding of a quarter of a circle. A schematic view of the pinch showing the pinch shape is presented in Fig. 1.

\subsection{Measurement setup}

\subsubsection{Test compressor and test stand}

The experiments were conducted at a compressor test stand placed in the Laboratory of Fluid Dynamics at Lappeenranta University of Technology. The test stand layout is presented in Fig. 2. The test compressor is a one-stage high-speed industrial centrifugal compressor, operated as it would be under normal operation. The compressor is driven directly by a high-speed electric motor, and the rotational speed is adjusted with a variable-speed drive. The compressor is equipped with magnetic bearings. The compressor intakes from and discharges into the atmosphere.

The compressor design pressure ratio $\pi_{\mathrm{tt}}$ is 1.78 , and the specific rotational speed, defined as 


$$
N_{s}=\frac{\Omega \sqrt{q_{v}}}{\Delta h_{s}^{0.75}}
$$

is 0.8. The impeller design operating point Mach number and Reynolds number, defined as in the standard [15], are 0.92 and $4.4 \cdot 10^{5}$, respectively. The test compressor impeller has seven full and seven splitter blades with a $40^{\circ}$ back sweep from the radial direction. The ratio of the rotor outlet height to the outlet radius $b_{2} / r_{2}$ is 0.1214 .

The test compressor has an axial inlet and it is equipped with a volute, designed to provide a constant circumferential pressure distribution at the design mass flow. An exit cone is placed after the volute in order to mount the compressor stage to standard piping.

The efficiency and pressure ratios of the compressor stage are measured by using the pressure and temperature measurements of the test stand. The air enters the compressor through a mass flow nozzle, a flow straightener and a throttling valve. The mass flow nozzle is an ISA 1932 nozzle made according to the DIN 1952 standard [13]. The performance calculations of the compressor and the instrumentation of the test stand are carried out according to standards $[14,15,16,17]$.

\subsubsection{Flow field measurements}

Detailed flow field measurements in the diffusers were conducted using a three-hole cobra probe, Kiel probes, and static pressure taps. The flow angle and total pressure were measured with the cobra probe and the total temperature and pressure with the Kiel probes at the diffuser inlet and outlet. The radius ratios of the cobra probe and Kiel probe measurements were $r / r_{2}=1.054$ and $r / r_{2}=1.67$. The traverses were made over the diffuser width. The cobra and Kiel probe measurements were made at four different circumferential positions so that that the cobra probe was traversed opposite of the 
volute tongue, and the Kiel probes were traversed at the three other locations. The cobra probe head width compared to diffuser width is 0.074 and the Kiel probe head width compared to the diffuser width is 0.196 . The Kiel probe size is rather large compared to the diffuser width but it is only used for total temperature measurements. The blockage formed by probes is minimal since flow area at the diffuser inlet and outlet is large. Area ratio of probes and flow area at the diffuser inlet is 0.00198 .Static pressure measurements were also conducted in the diffuser inlet and outlet at four different circumferential positions adjacent to total pressure measurement locations. The static pressure taps were located at the shroud at the diffuser inlet and at the hub at the diffuser outlet. The same radius ratio was used for the static pressure measurements as in the probe measurements. The locations of the probe measurements and the static pressure taps are shown in Fig. 3. The flow fields were measured at the design rotational speed, with three different mass flows: $0.55,1.0$, and 1.35 times the design mass flow. For readability these points will be referred to in the text as "low flow", "design flow", and "high flow", respectively. The low flow operating point is quite close to the minimum stable operating point (safe to operate the compressor without risking the stall/surge) which is at $q_{\mathrm{m}, \mathrm{min}} / q_{\mathrm{m}, \mathrm{des}}=0.52$, and the high flow operating point is close to the choke which is at $q_{\mathrm{m}, \text { choke }} / q_{\mathrm{m}, \mathrm{des}}=1.38$. The maximum relative measurement uncertainties, with 95.4\% confidence interval are listed in Table 2.

\section{Measurement results}

\subsection{Impeller, diffuser and volute performance}

The total-to-static efficiency from the compressor inlet to the diffuser outlet is defined as

$$
\eta_{\mathrm{ts}, 13}=\frac{T_{\mathrm{s} 3}-T_{\mathrm{t} 1}}{T_{3}-T_{\mathrm{t} 1}}
$$

and for the impeller the efficiency is defined similarly, but the impeller exit temperatures are used instead (subscript 3 is replaced with 2). 
When the efficiency and pressure ratios of the pinched designs are studied, they are compared to the corresponding values of the unpinched design, e.g.

$$
\eta=\frac{\eta_{\text {pinched }}}{\eta_{\text {unpinched }}}
$$

The pressures and temperatures are mass flow averaged when the pressure ratios and efficiencies are calculated. The total-to-static efficiencies and pressure ratios are presented in Tables 3 and 4, respectively. When the impeller efficiency is examined, it is evident, in general, that the impeller performance is better with the pinched designs than with the unpinched design at all mass flows tested. At the design flow, the efficiency increment is approximately 7-10 percentages for the shroud pinched designs, and 3-7 percentages for the hub and shroud pinched designs. This confirms that the pinch increases the impeller efficiency. On the other hand, when the impeller efficiencies are compared to the efficiencies over the impeller and diffuser, the efficiency increment over the impeller and diffuser is lower than the increment of the impeller efficiency alone. This indicates that whilst the pinch improves the impeller efficiency it hinders the diffuser performance. Also, when the cases where pinch is implemented only to the shroud are compared to cases where the pinch is added to both walls, the cases with only shroud pinch are better in general. The effect of pinch is highest at the high mass flow and lowest at the low mass flow, but the trends are similar. At the high flow, the two cases with most shroud pinch perform noticeably worse than any other designs. This is most likely due to them operating under choke.

The pressure ratios behave like efficiencies. The pressure ratios are higher with the pinched designs. Unlike with the efficiency the effect is most evident at the design flow. In general, all the pinched designs are as good. As with the efficiency, the pressure ratios over the impeller and diffuser combined are the same as the pressure ratios over the impeller alone. This strengthens the point that pinch seems to deteriorate the diffuser performance. 
Reducing the diffuser width, improves the impeller efficiency and pressure ratio but deteriorates the diffuser performance, if the reduction is reasonable. In general, width reduction in the shroud is better than reduction implemented at the shroud and the hub walls, and the width reduction in the shroud must be sufficient to obtain positive outcomes in the impeller.

\subsection{Flow fields}

\subsubsection{Design flow}

The absolute flow angles, measured from the radial direction, before and after the diffuser are presented in Fig. 4. After the impeller, all pinched designs have clearly more radial flow near the shroud. This indicates that the pinch reduces the secondary flow region present near the shroud. The back flow present with the unpinched design is suppressed with the pinch. The larger the pinch is, the larger the change in the flow angle is. After the diffuser, the effect is similar. The flow near the shroud is more radial, and the flow field is more uniform. The pinch affects the flow field more near the shroud than near the hub, and if the pinch is implemented only to the shroud, the flow field near the hub is unaffected.

The absolute velocities have been calculated using the total pressure measured with the cobra probe, the static pressure measured with the closest mounting, and the total temperature measured with two adjacent Kiel probes (mean value). The static pressure is assumed to be constant over the height of the diffuser. The velocities before and after the diffuser are presented in Fig. 5.

The secondary flow region near the shroud is evidently smaller with the pinched designs, but the velocity profile is still skewed towards the shroud. Even though the secondary flow region is smaller with the pinched designs, the velocity still reduces rapidly close to the shroud. This indicates that the boundary layer is thicker at the shroud than at the hub also with the pinched designs. A similar effect is also seen in the velocity profiles after the diffuser, but the difference in the boundary layer thickness 
between the hub and shroud is less drastic. The velocities at diffuser outlet are higher when the pinch is applied to the hub and the shroud than when pinch is only applied to the shroud. Further, the velocity profiles are flatter when pinch is applied only to the shroud. Flat velocity profiles indicates less shear, and thus lower viscous losses and lower drain of kinetic energy into turbulence at free stream. While the free stream shear is decreased, the wall shear is increased due to higher velocities. When further increasing the pinch, this will overcome the benefits of free stream shear reduction. It is evident that the total to static efficiency would decrease if the effect of the pinch would be only accelerating the flow by reducing the static pressure. Nevertheless, we obtain increase in the total to static pressure ratio and in efficiency. The only possible physical explanation is that kinetic energy is converted to pressure rise more efficiently.

The radial velocities have been calculated using the flow angle and the velocity magnitude. The radial velocity is defined as

$$
c_{\mathrm{r}}=c \cdot \cos \alpha
$$

The radial velocities before and after the diffuser are presented in Fig. 6. After the impeller, the radial velocity is higher near the hub than near the shroud with all the designs. The differences in the radial velocity between the different designs near the hub are minor. Near the shroud the differences are evident. The narrower the diffuser is, the higher the radial velocity. The secondary flow region near the shroud is significantly smaller with the pinched designs. Pinch decreases the boundary layer at the hub and at the shroud. Furthermore, the unpinched case shows a large area of reversed flow near the shroud. This causes the rest of the flow to accelerate, to satisfy the continuity equation. This phenomenon is not as pronounced with the pinched designs, and the shroud pinch clearly seems to suppress this behaviour. Higher radial velocity near the hub is also visible at the diffuser outlet. After the diffuser, the pinched designs have higher radial velocity near the shroud than the unpinched one. The 
two designs with the most shroud pinch have the highest radial velocity near the shroud, and it is close to what they have near the hub.

The secondary flow region near the shroud is strongly associated with the losses caused by the tip clearance flow. As this secondary flow region is smaller with the pinched designs, it indicates that the pinch is inexpensive and simple way to counter the losses associated with the tip clearance.

\subsubsection{Off-design conditions}

The behaviour of the flow fields at the off-design conditions is quite similar to that at the design flow. The flow angles and radial velocities at the low mass flow are presented in Fig. 7 and Fig. 8, respectively. The differences between the different pinched designs are minor, but the difference between the pinched designs and the unpinched design is higher with the low flow. After the impeller, the secondary flow region is significantly lower, and the flow fields are more uniform. After the diffuser, the secondary flow region near the shroud still exists, but is smaller when the diffuser height is decreased sufficiently.

The flow angles and radial velocities at the high flow are in general similar to those at the low flow and at the design flow. The effect of pinch is larger and differences between the different pinched geometries are more evident at the high flow but the velocity distributions are similar, and hence are not presented here.

An increase in adverse effects of tip clearance flow with increasing mass flow are reported e.g. in [18] and [19], and as the effects seen of pinch were higher at the higher mass flow further strengthens the point that the pinch counters the adverse effects caused by the tip clearance flow.

\section{Conclusions and discussion}


Seven different vaneless diffusers were studied experimentally. One design was a basic unpinched diffuser, and the six others had pinch implemented either at the shroud or at the shroud and the hub walls. The impeller and diffuser were studied. In addition the flow fields were investigated at the design mass flow and at high and low mass flows. The flow field measurements were made with a cobra probe and Kiel probes, and static pressure measurements. The total temperature was measured with the Kiel probes.

The pinch increased the total-to-static efficiency and pressure ratio of the impeller at all mass flows. The largest increments were seen at the highest mass flow, except for the two diffusers with most shroud pinch, which were choked at the high flow. When the improvements in the efficiency and pressure ratios were divided to the different components, it was observed that the impeller performance improved, and the diffuser performance decreased, when the pinch was implemented.

The pinch suppressed the reversed flow area present at the impeller exit near the shroud. The flow reversal is partly caused by the tip clearance effects. This indicates that the pinch decreases the losses caused by the tip clearance flow, and the fact that more benefits were seen at the high flow when the harmful effects of the tip clearance flow should be greater than at the low and design flows, strengthens this point.

One possible explanation for the reduced leakage losses is that with a subsonic impeller, like in this case, the pinch forces the flow towards the hub before reaching the actual pinch, reducing the tip leakage flow. If this is the case, then the positive effects of pinch should be greater when the flow velocity is lower at the impeller exit, and vice versa.

Whether the leakage flow is the dominant factor in reversing the flow, could be validated by replicating the measurements with a shrouded impeller. Should the reverse flow region be absent or less pronounced in the unpinched case, it would prove that tip clearance effects indeed cause flow 
reversal. Studying pinch with a shrouded impeller might also indicate whether the improved efficiency is due to reduced tip leakage flow.

It was found that the outlet velocity of the diffuser at pinched geometries were higher than in unpinched cases. Yet, the total to static pressure rise was higher and simultaneously total to static efficiency was higher. The shroud pinch clearly re-energised the reversed flow area near the shroud, the effects were seen clearly just after diffuser inlet. Interestingly, the mean velocity near the hub in the unpinched case was the highest just after the diffuser inlet. This was due to flow separation at shroud. This indicates that static pressure rise in rotor was wasted to accelerate the flow past the separation point. In the shroud pinched cases, the deliberate acceleration of the flow at the diffuser inlet led to smaller losses, as the effective flow area at measurement point was actually larger.

The diffuser outlet area decreases as the pinch increases, therefore, assuming no flow separation, the outlet velocities should be higher, as was observed. Therefore, it is plausible that the total to static efficiency of the stage would further improve if the radius of the pinched diffuser would be increased. The free stream shear of the pinched geometries was smaller, thus they should generate less free stream losses per unit length.

All in all, the pinch improved the stage efficiency and pressure ratio. This improvement was due to the higher efficiency and pressure ratio at the measurement location after the impeller outlet. The better impeller performance was seen with almost every design, except the one with the least shroud pinch. For this diffuser the shroud pinch was approximately the same as the tip clearance during operation. This indicates that in order to get the possible benefices of pinch, the pinch should be higher than the tip clearance. Pinch in the hub is not recommended.

In this study the diffuser was modified only by changing its height. However, when using a pinched diffuser, the diffuser can be designed to be longer without the operational range becoming narrower. 
Because the flow field at the diffuser outlet was changed due to the pinch, the volute could also be redesigned. By changing the diffuser length and redesigning the volute, the performance improvement achieved by the pinched diffuser should be even higher than the one observed in this study.

\section{Acknowledgements}

The authors gratefully acknowledge the financial contribution of the Academy of Finland, the Finnish Funding Agency for Technology and Innovation - TEKES, and High Speed Tech Oy Ltd., for their part in financing the research. 


\section{Nomenclature}

\section{Latin alphabet}

$b \quad$ diffuser width, $\mathrm{m}$

c absolute flow velocity, $\mathrm{m} / \mathrm{s}$

$C_{\mathrm{pr}} \quad$ static pressure rise coefficient

E relative error, \%

$K_{\mathrm{p}} \quad$ total pressure loss coefficient

$h \quad$ specific enthalpy, $\mathrm{J} / \mathrm{kg}$

$N \quad$ rotational speed, $1 / \mathrm{s}, \mathrm{rpm}$

$N_{\mathrm{s}} \quad$ specific rotational speed

$p \quad$ pressure, $\mathrm{Pa}$

$q_{\mathrm{m}} \quad$ mass flow, $\mathrm{kg} / \mathrm{s}$

$q_{\mathrm{v}} \quad$ volume flow, $\mathrm{m} 3 / \mathrm{s}$

$r \quad$ radius, $\mathrm{m}$

$T \quad$ temperature, $\mathrm{K}$

\section{Greek alphabet}

$\alpha \quad$ absolute flow angle, ${ }^{\circ}$

$\eta \quad$ efficiency

$\Omega \quad$ angular velocity, $\mathrm{rad} / \mathrm{s}$

$\pi \quad$ pressure ratio

\section{Subscripts}

1 compressor inlet

2 impeller outlet

2 beginning of pinch 
3 diffuser outlet

r radial component

$\mathrm{s} \quad$ isentropic

t total

ts total-to-static

\section{References}

[1] Senoo Y., and Kinoshita, Y., "Influence of inlet flow conditions and geometries of centrifugal vaneless diffusers on critical flow angle for reverse flow", Journal of Fluids Engineering, Vol. 99, No. 1, pp. 98-103, 1977.

[2] Van den Braembuscsche, R. A., Frigne, P., and Roustan, M., "Rotating Non-Uniform Flow in Radial Compressors", AGARD 55 $5^{\text {th }}$ B Specialist meeting of PEP, 282, paper 12, May 7-9, Brussels, Belgium, 1980.

[3] Abidogun, K. B., "Effects of Vaneless Diffuser Geometries on Rotating Stall", ASME $4^{\text {th }}$ International Pipeline Conference, IPC2002-27203, September 29-October 3, Alberta, Canada 2002.

[4] Engeda, A., "Experimental and numerical investigation of the performance of a $240 \mathrm{~kW}$ centrifugal compressor with different diffusers", Experimental Thermal and Fluid Science, Vol 28, No. 1, pp. 5572, 2003. 
[5] Ludtke, K., "Aerodynamic tests on centrifugal process compressors - the influence of vaneless diffuser shape", Journal of Engineering for Power, Vol. 105, No. 4, pp. 902-909, 1983.

[6] Ferrara, G., Ferrari, L., Mengoni, C. P., Lucia, M. D. and Baldassarre, L., “Experimental investigation and characterization of rotating stall in a high pressure centrifugal compressor: Part I: Influence of diffuser geometry on stall inception", ASME Turbo Expo, GT2002-30389, June 3-6, Amsterdam, the Netherlands, 2002.

[7] Ferrara, G., Ferrari, L., Mengoni, C. P., Lucia, M. D. and Baldassarre, L., “Experimental investigation and characterization of rotating stall in a high pressure centrifugal compressor: Part II: Influence of diffuser geometry on stage performance", ASME Turbo Expo, GT2002-30390, June 3-6, Amsterdam, the Netherlands, 2002.

[8] Cellai, A., Ferrara, G., Ferrari, L., Mengoni, C. P. and Baldassarre, L., "Experimental investigation and characterization of rotating stall in a high pressure centrifugal compressor: Part III: Influence of diffuser geometry on stall inception and performance ( $2^{\text {nd }}$ impeller tested)", ASME Turbo Expo, GT2003-38390, June 16-19, Atlanta, Georgia, USA, 2003.

[9] Tang, J. Computational Analysis and Optimization of Real Gas Flow in Small Centrifugal Compressors, Ph. D. Dissertation, Institute of Energy, Lappeeranta University of Technology, Finland, 2006. 
[10] Turunen-Saaresti, T., Reunanen A. and Larjola J. Computational and experimental study of pinch on the performance of a vaneless diffuser of a centrifugal compressor. Journal of Thermal Science, Vol. 15, No. 4, pp. 306-313, 2006.

[11] Turunen-Saaresti, T., Grönman A., and Jaatinen A., "Experimental Study of Pinch on the Performance of a Vaneless Diffuser of a Centrifugal Compressor", ASME Turbo Expo, GT2009-60162, June 8-12, Orlando, Florida, USA, 2009.

[12] Jaatinen A., Grönman, A., Turunen-Saaresti, T., and Röyttä, P, “Effect of Vaneless Diffuser Width on the Overall Performance of a Centrifugal Compressor", Proceedings of the Institution of Mechanical Engineers, Part A: Journal of Power and Energy, Vol. 225, pp 665-673, 2011.

[13] DIN 1952, Durchflußmessung mit genormten Düsen, Blenden und Venturdüsen, Deutsches Institut für Normung e.V. 1971.

[14] ASME PTC 10, ASME Power Test Codes, compressors and exhausters. The American Society of Mechanical Engineering, 1965.

[15] ISO 5389, Turbocompressors - Performance test code. International Standardization Organization, 1992.

[16] VDI 2045 Part 1, Abnahme- und Leistungsversuche an Verdichtern, Versuchsdurchführung und Garantievergleich (Acceptance and Performance Test on Turbo Compressors and Displacement 
Compressors, Test Procedure and Comparison with Guaranteed Values). Verein Deutscher Ingenieure, 1993.

[17] VDI 2045 Part 2, Abnahme- und Leistungversuche an Verdichtern, Grundlagen und Beispiele (Acceptance and Performance Test on Turbo Compressors and Displacement Compressors, Theroy and Examples). Verein Deutscher Ingenieure, 1993.

[18] Mashimo, T., Watanabe, I., and Ariga, I., "Effect of fluid Leakage on performance of a centrifugal compressor", Journal of Engineering for Power, Vol. 101, No. 3, pp. 337-342, 1979.

[19] Senoo, Y., and Ishida, M., "Deterioration of compressor performance due to tip clearance of centrifugal impellers", Journal of Turbomachinery, Vol. 109, No. 1, pp. 55-61, 1987. 


\section{Figure captions}

Figure 1 A schematic view of the pinch

Figure 2 Layout of the test stand

Figure 3 Locations of probe and static pressure measurements

Figure 4 Absolute flow angles at the design flow. (a) hub \& shroud pinches before the diffuser, (b) hub \& shroud pinches after the diffuser, (c) shroud pinches before the diffuser and (d) shroud pinches after the diffuser

Figure 5 Absolute flow velocities at the design flow. (a) hub \& shroud pinches before the diffuser, (b) hub \& shroud pinches after the diffuser, (c) shroud pinches before the diffuser and (d) shroud pinches after the diffuser

Figure 6 Radial velocities at the design flow. (a) hub \& shroud pinches before the diffuser, (b) hub \& shroud pinches after the diffuser, (c) shroud pinches before the diffuser and (d) shroud pinches after the diffuser

Figure 7 Absolute flow angles at the low mass flow. (a) hub \& shroud pinches before the diffuser, (b) hub \& shroud pinches after the diffuser, (c) shroud pinches before the diffuser and (d) shroud pinches after the diffuser

Figure 8 Radial velocities at the low mass flow. (a) hub \& shroud pinches before the diffuser, (b) hub \& shroud pinches after the diffuser, (c) shroud pinches before the diffuser and (d) shroud pinches after the diffuser 


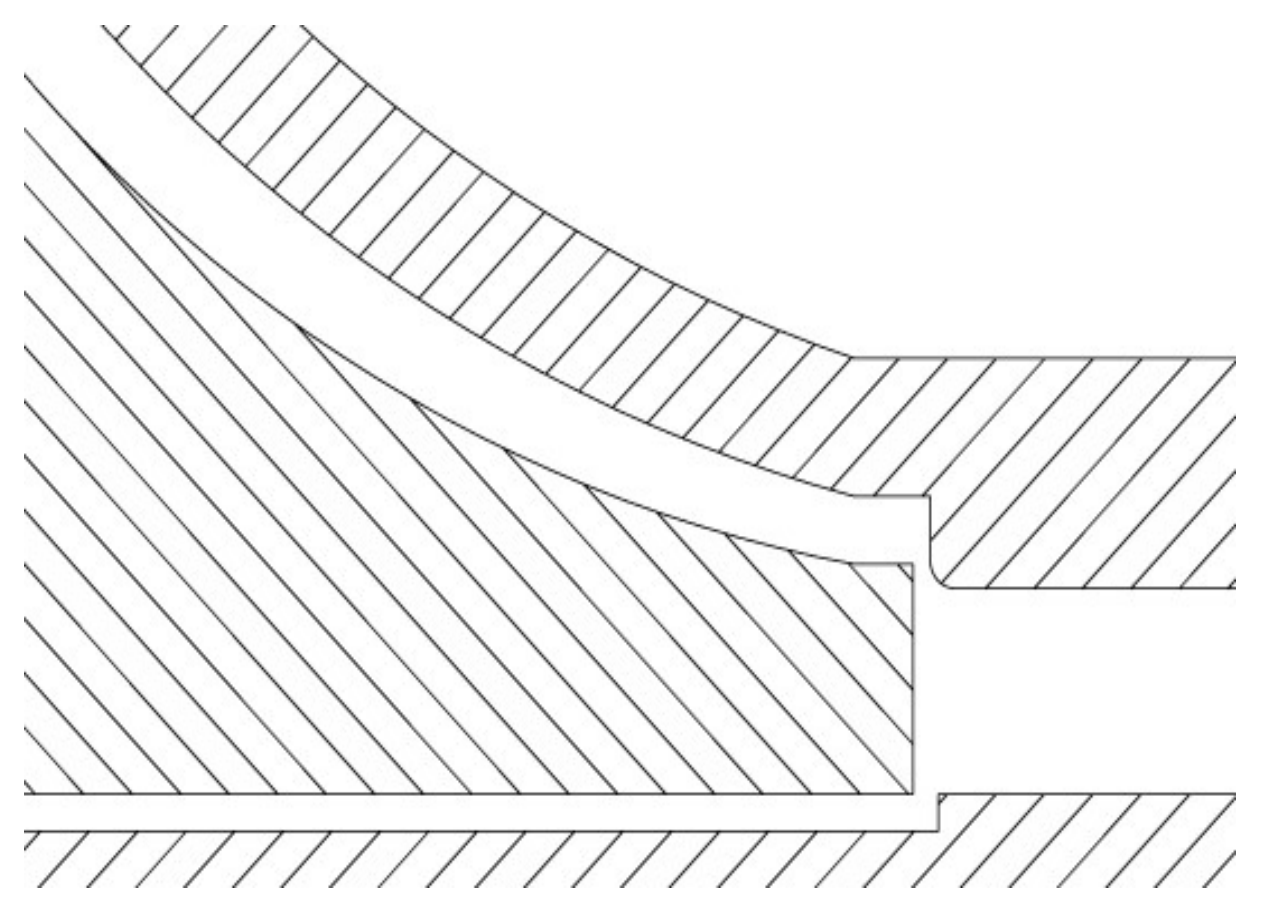

Figure 1 


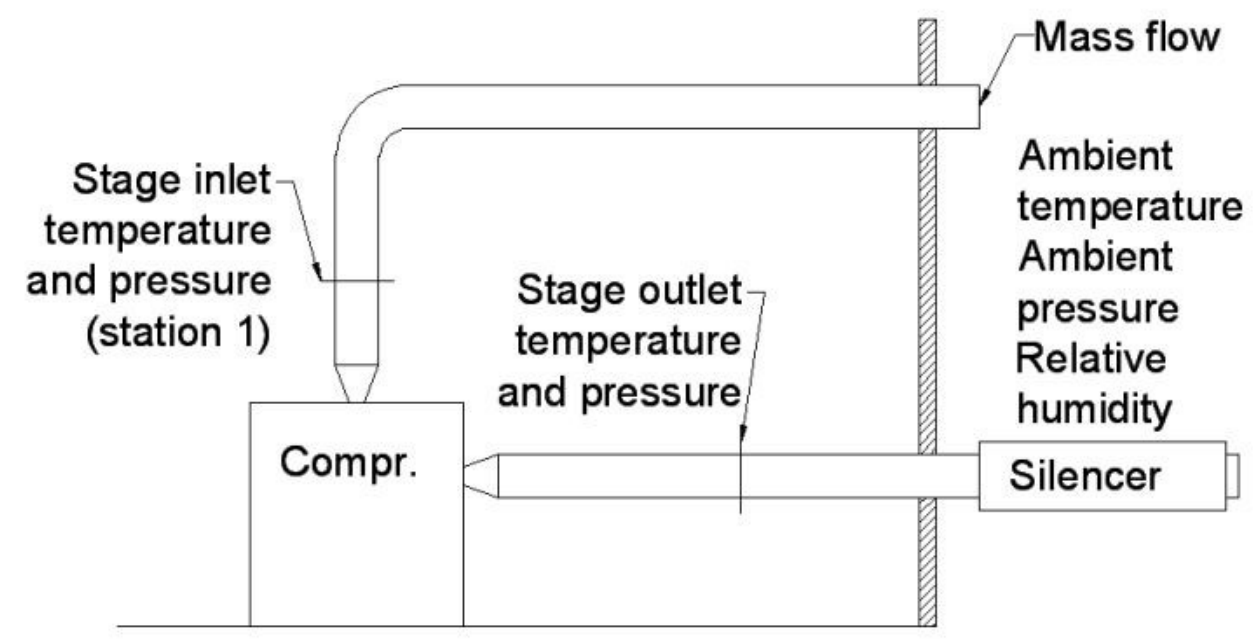

Figure 2 


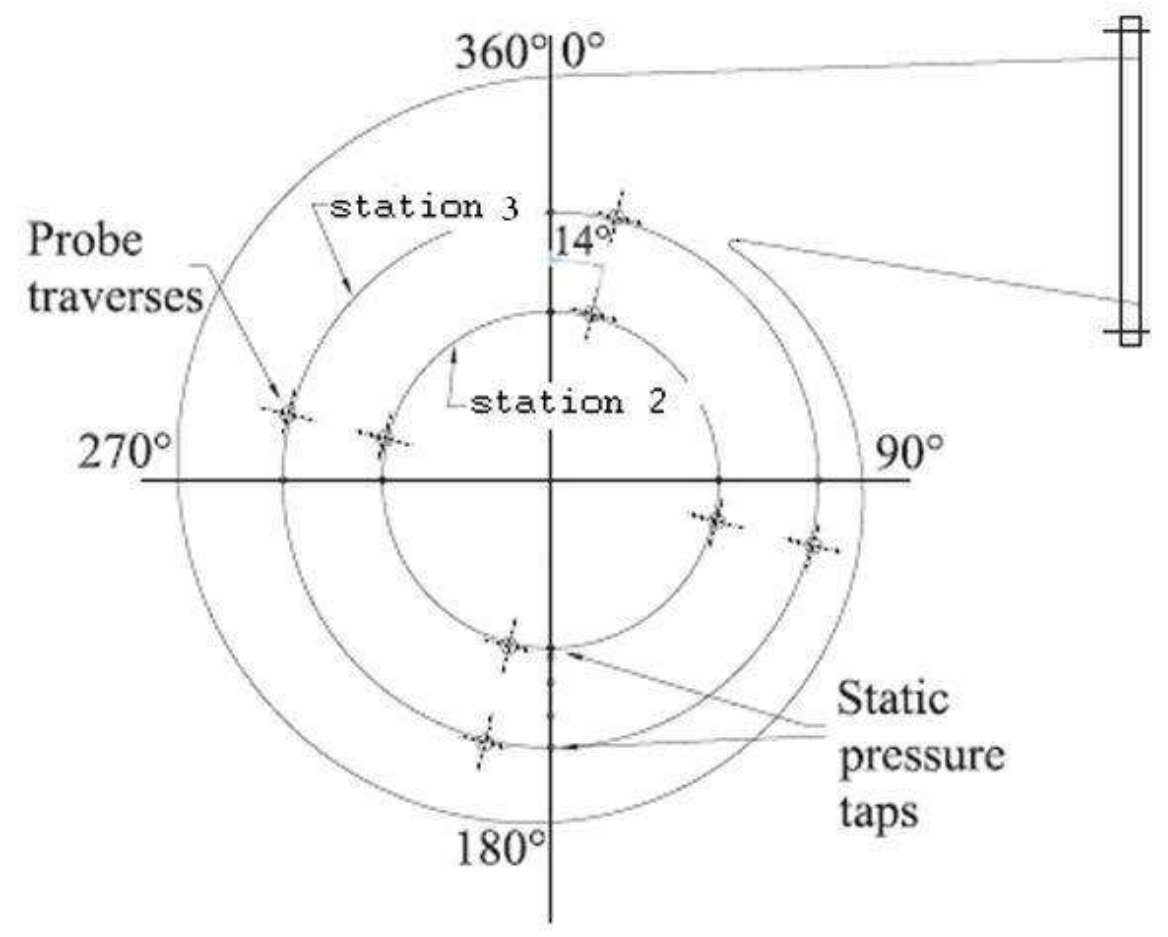

Figure 3 


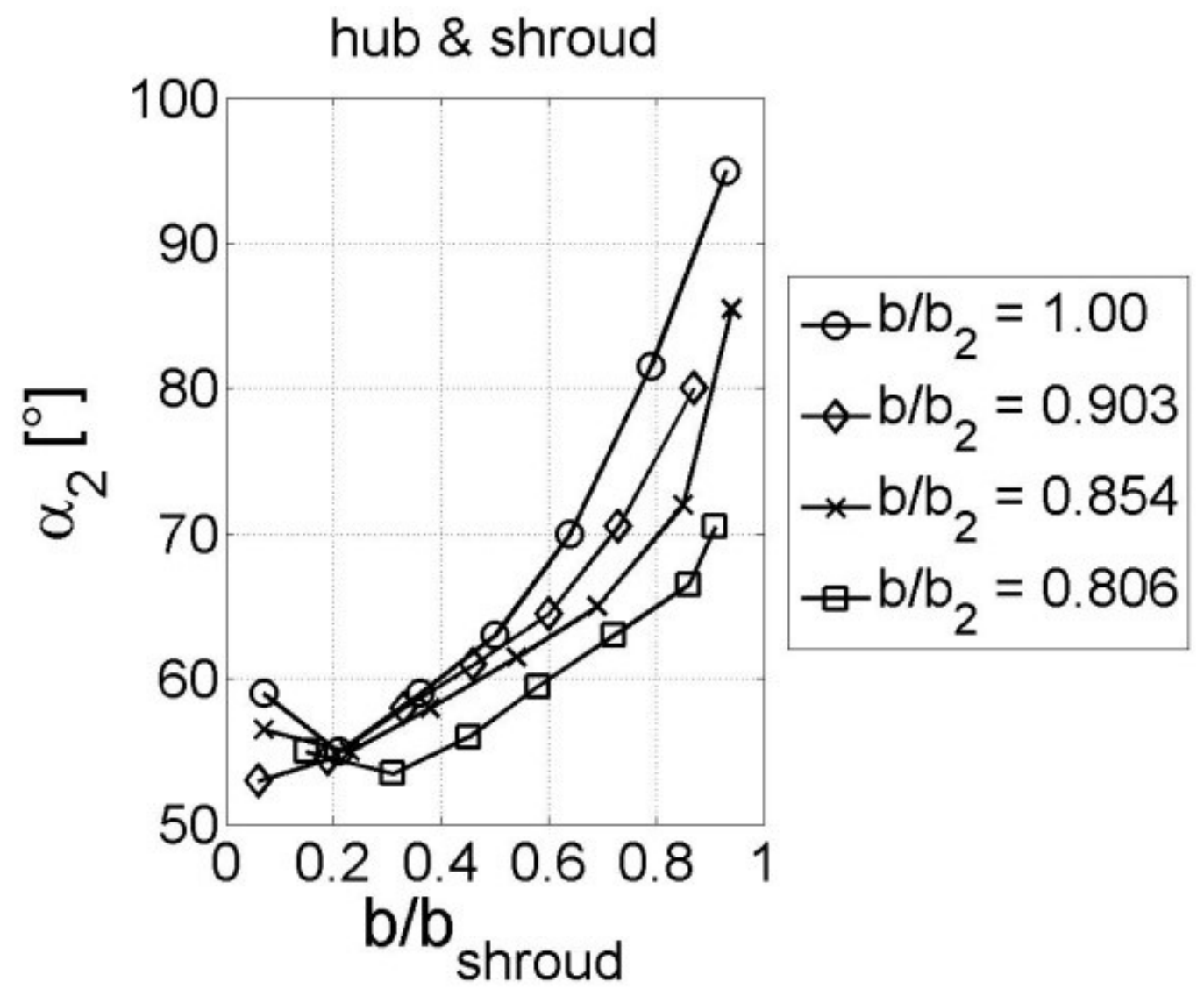

Figure 4a 


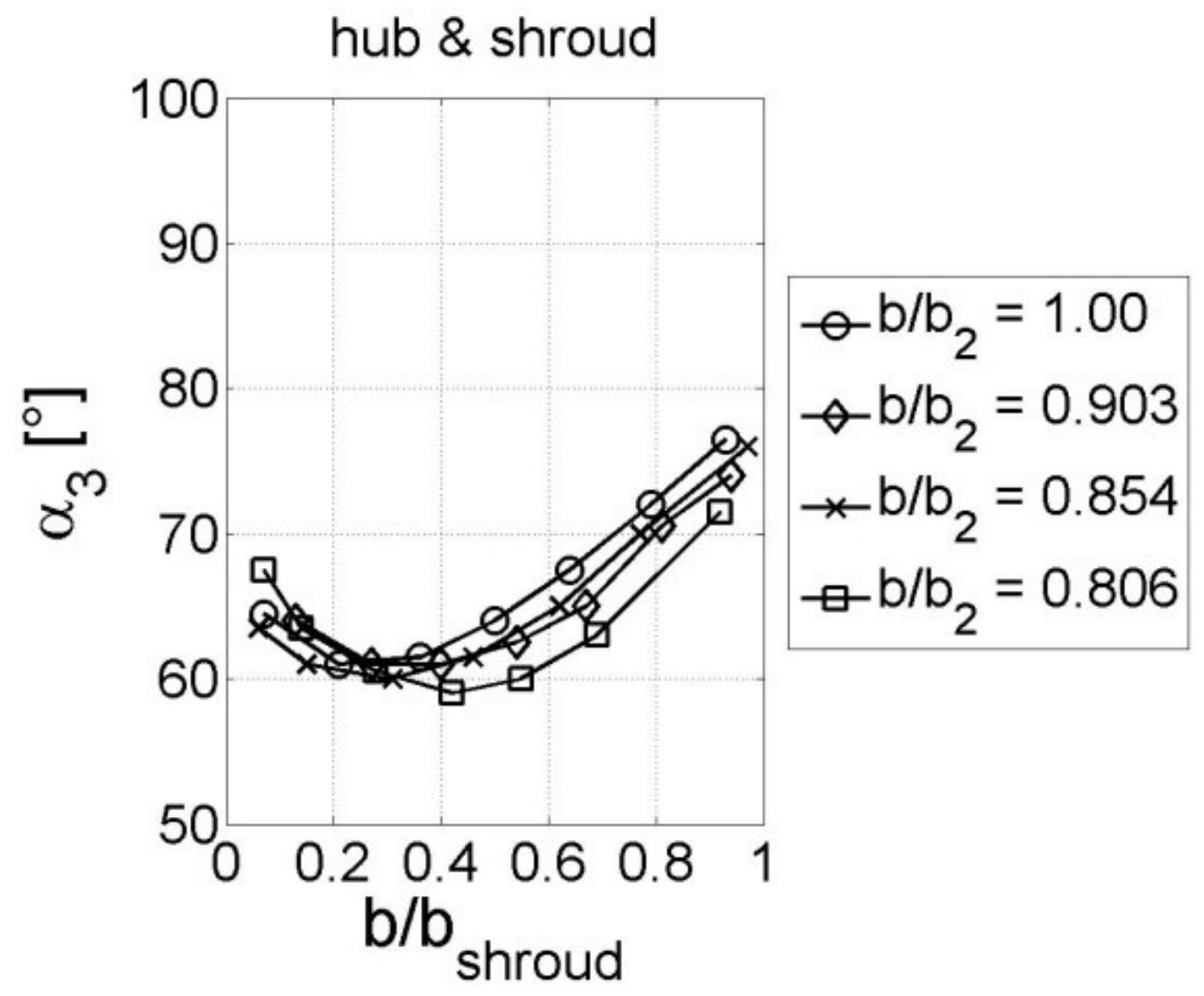

Figure 4b 


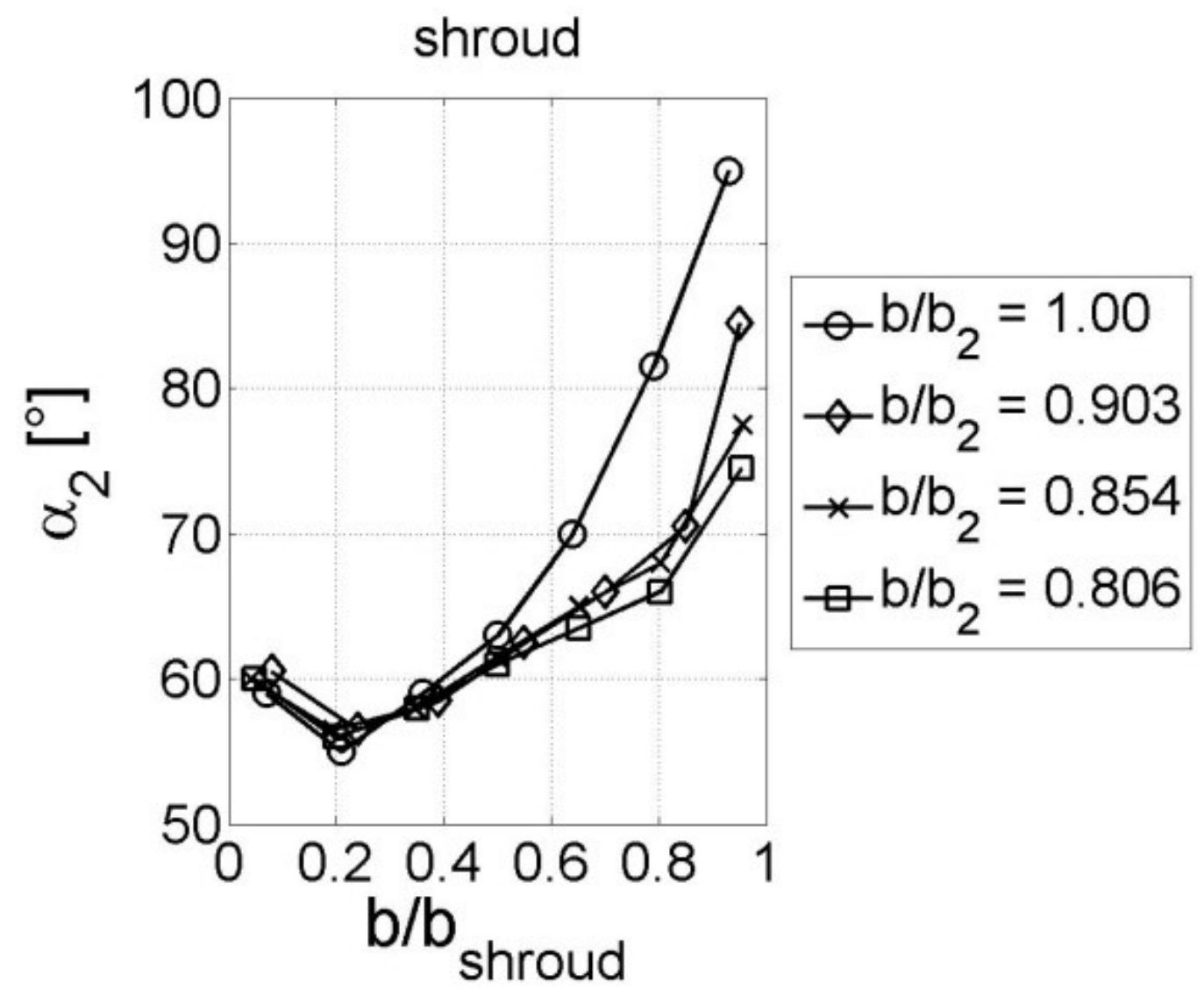

Figure 4c 


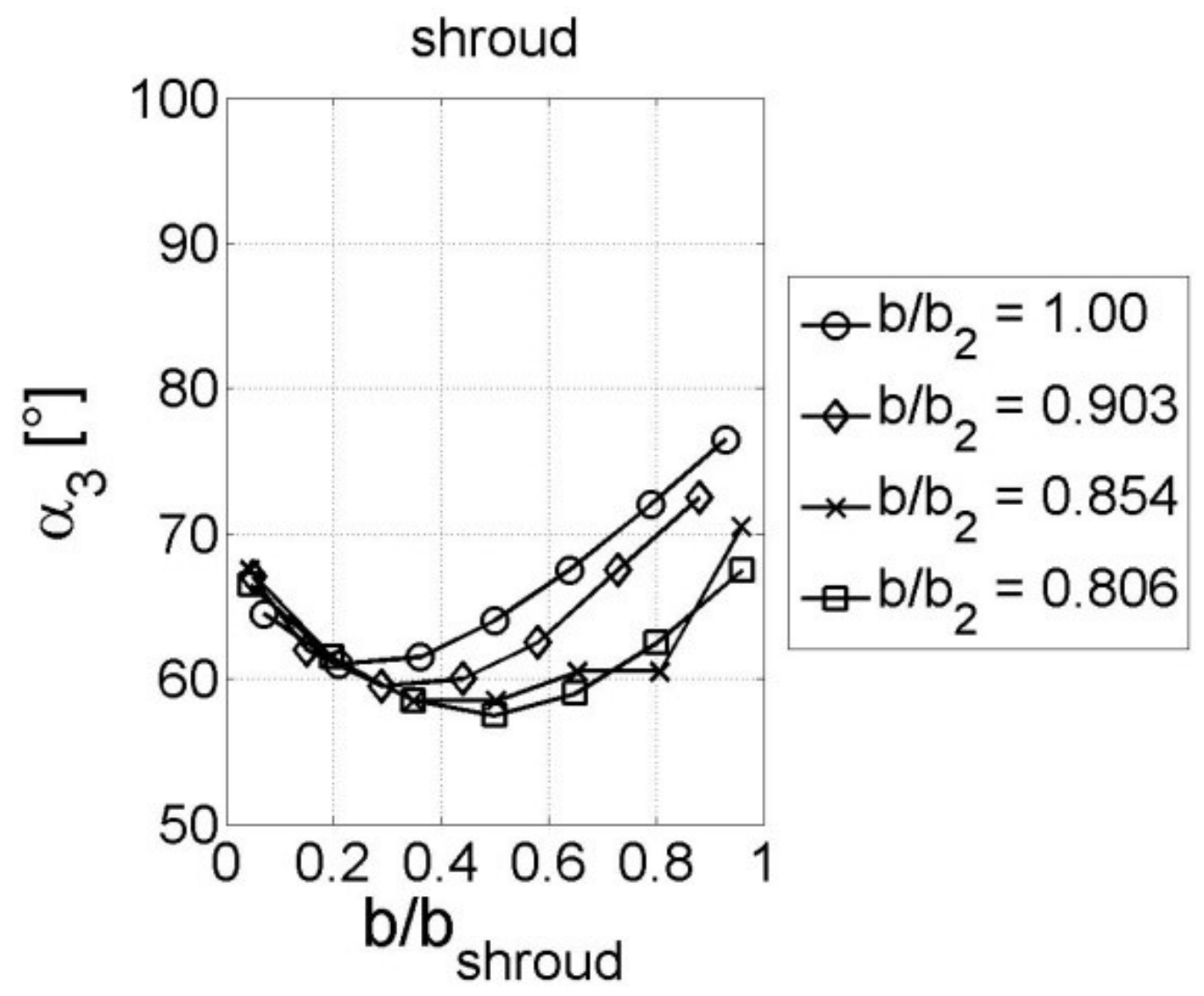

Figure 4d 


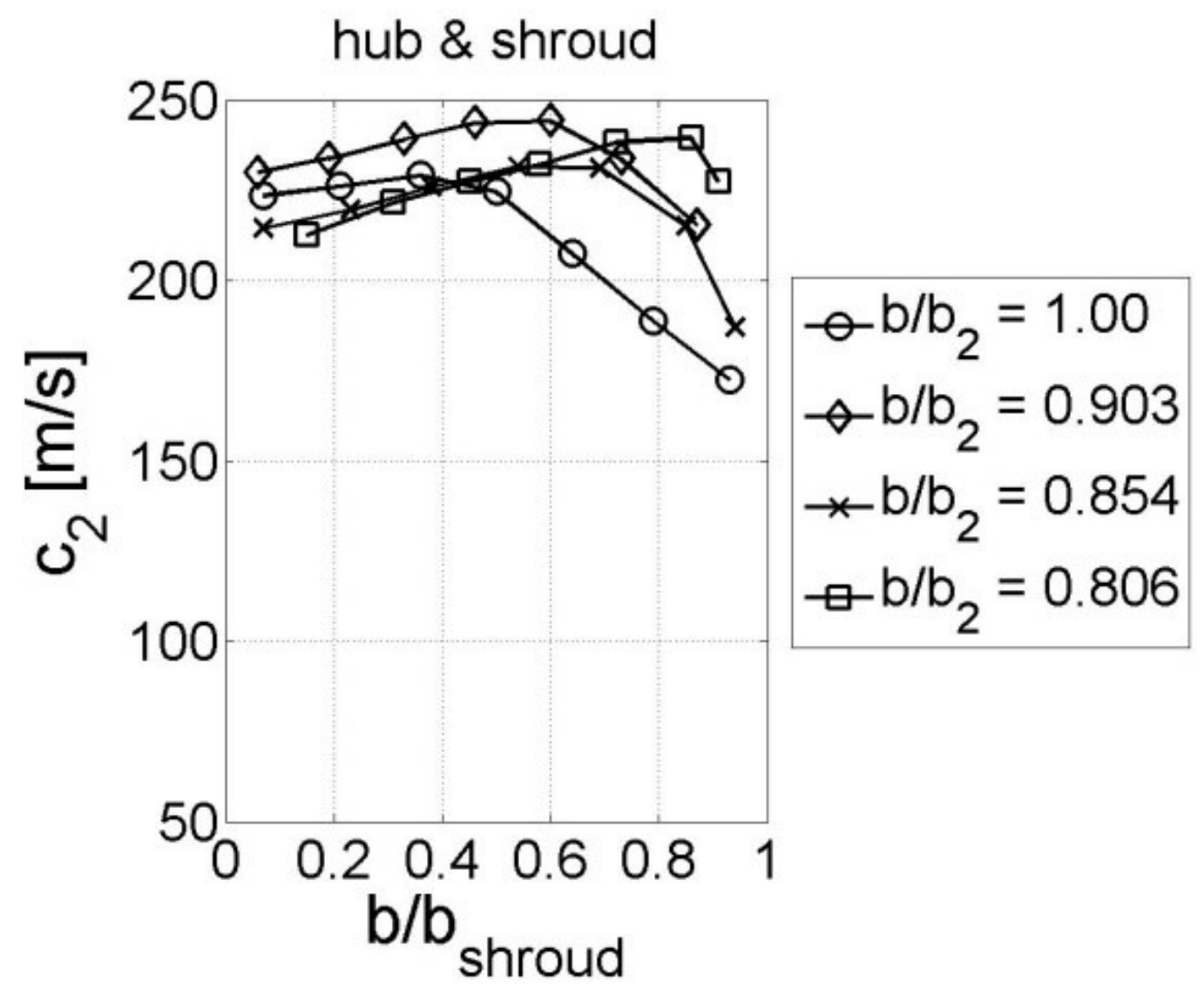

Figure 5a 


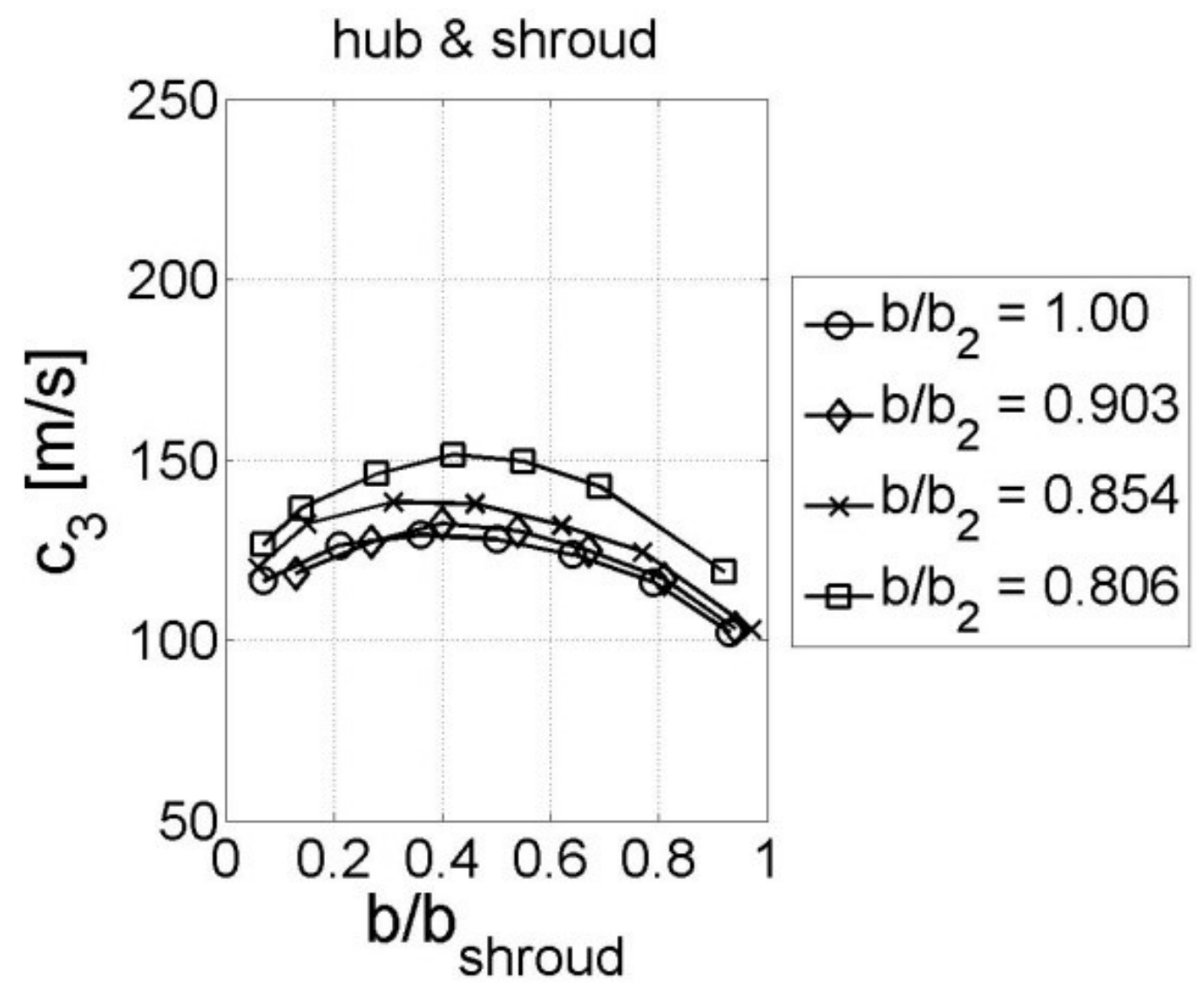

Figure 5b 


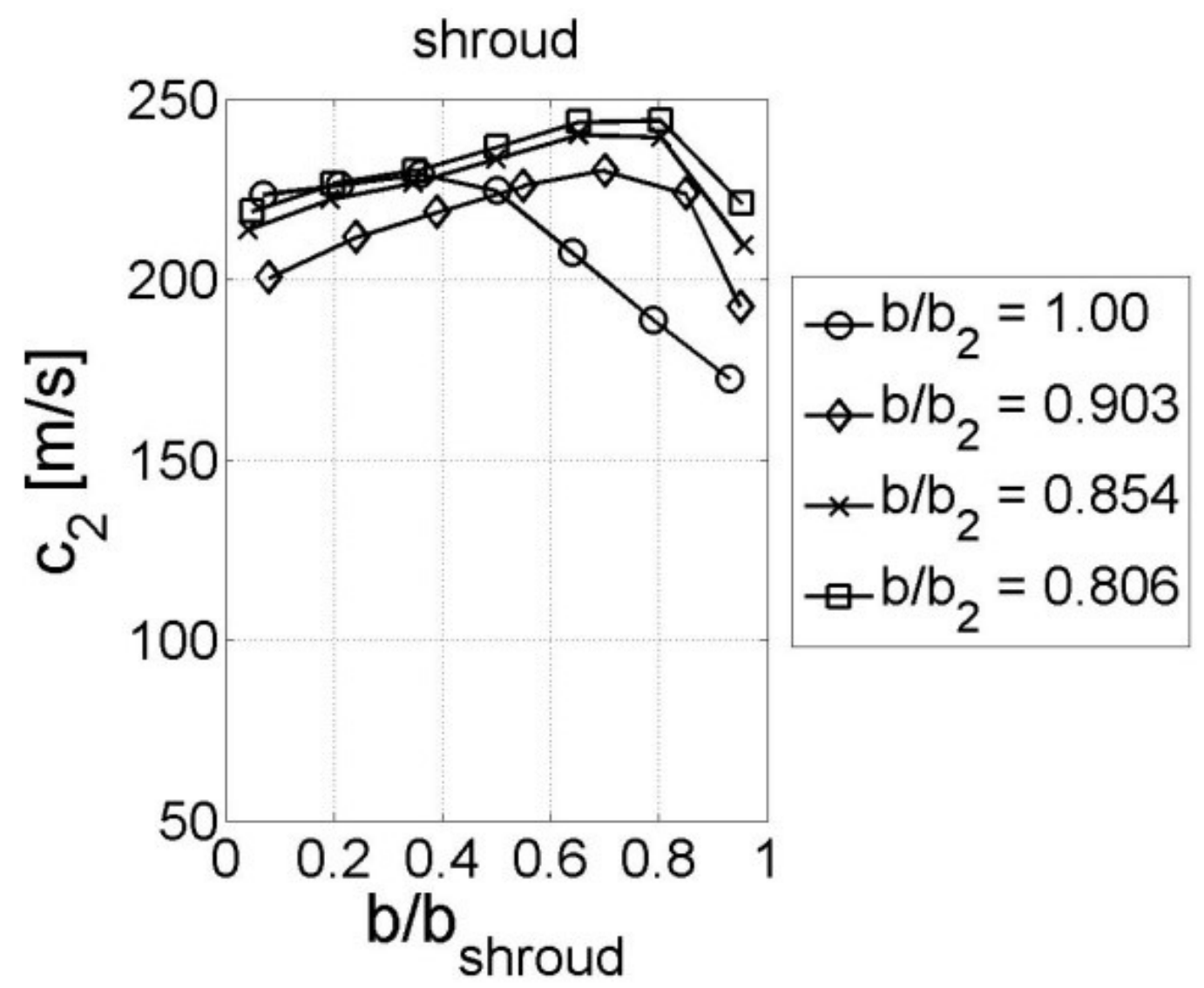

Figure 5c 


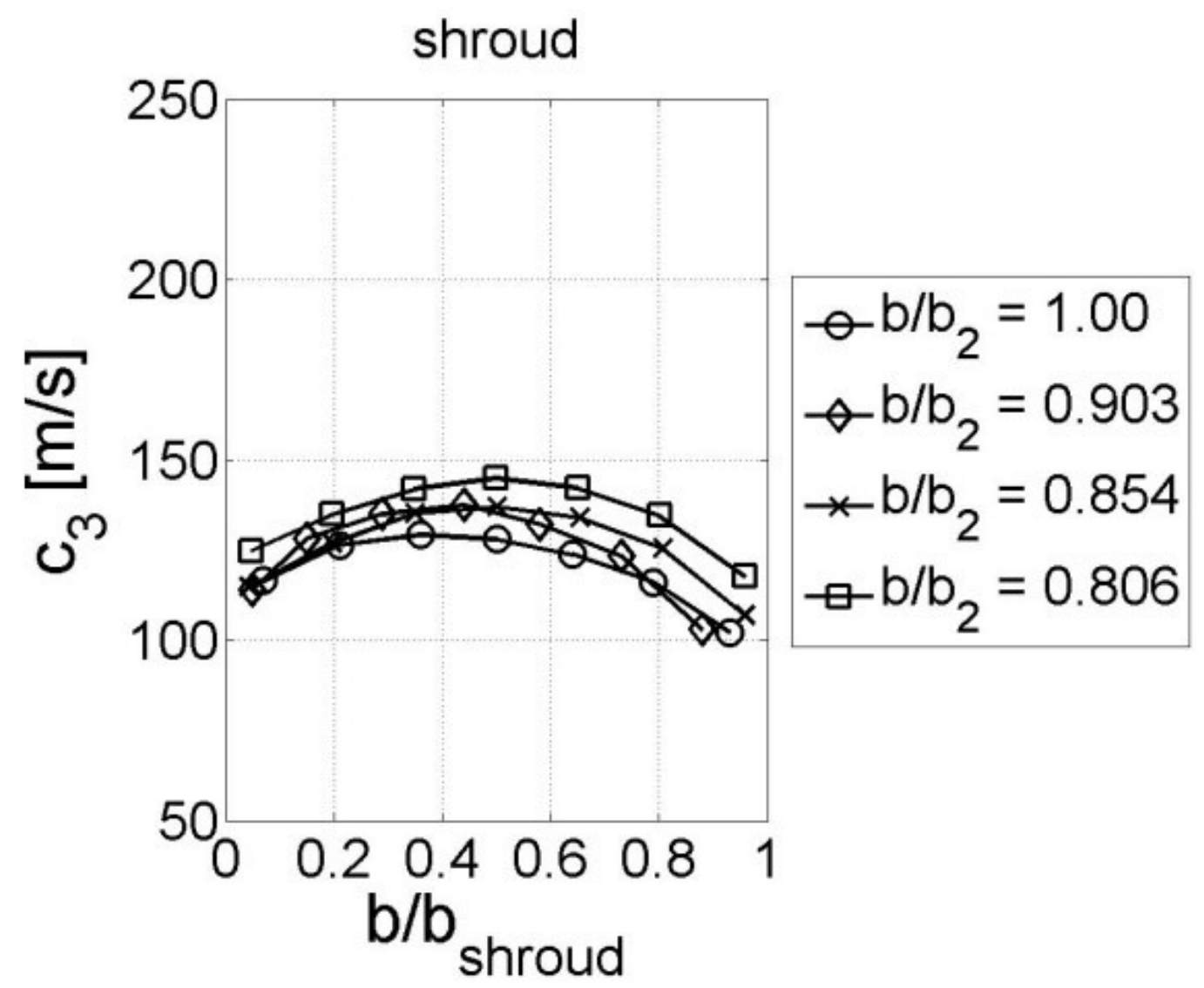

Figure 5d 


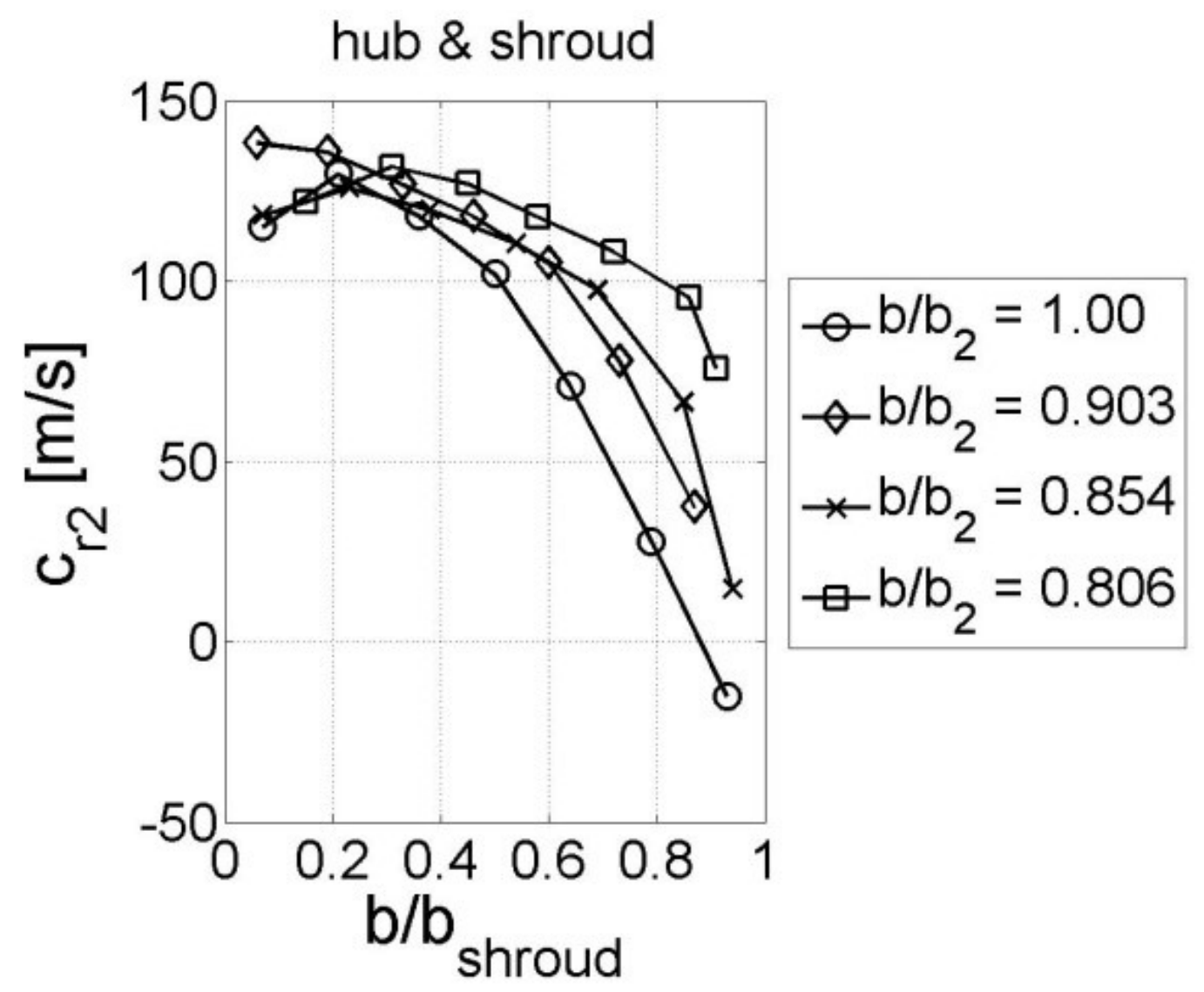

Figure 6a 


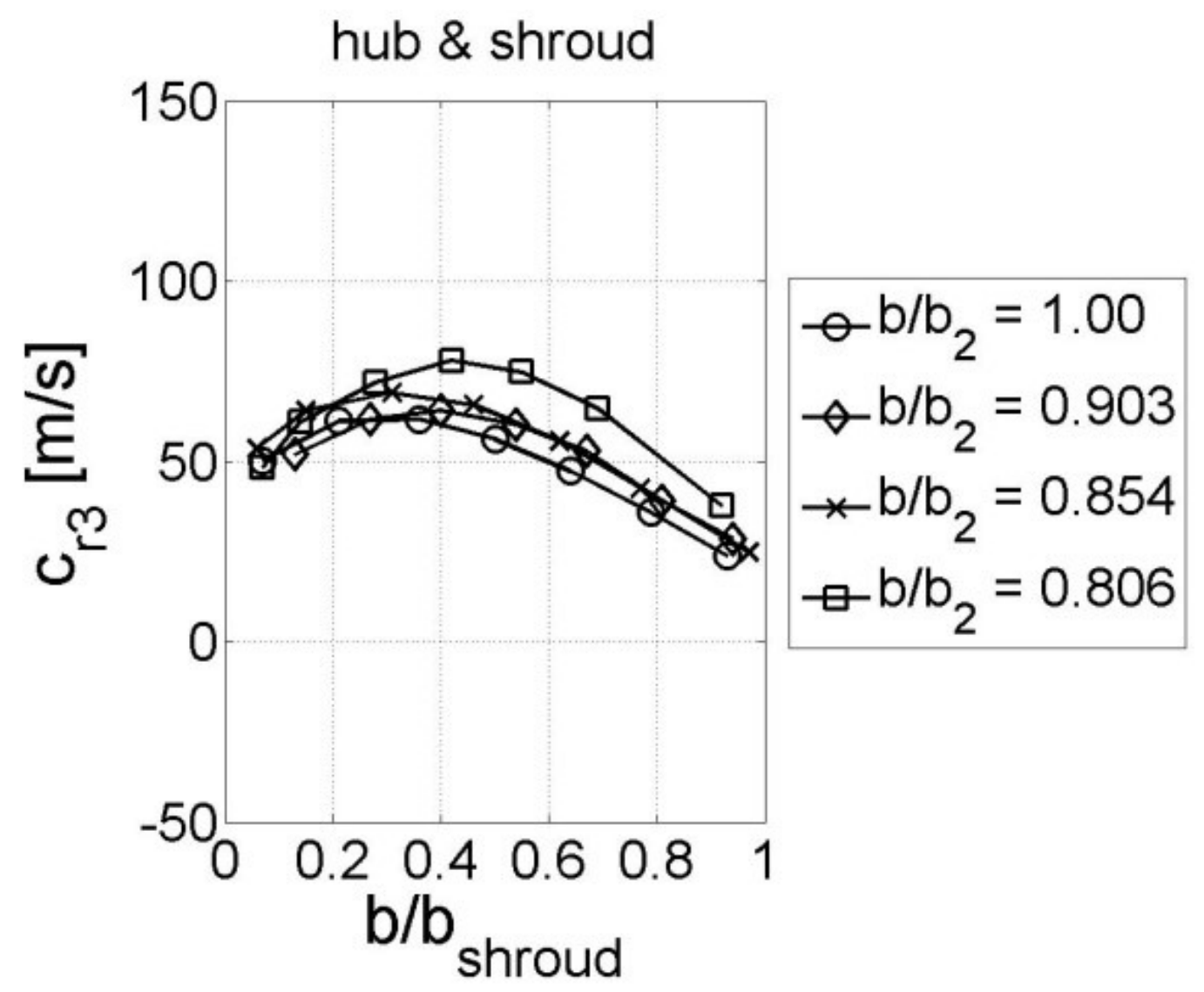

Figure 6b 


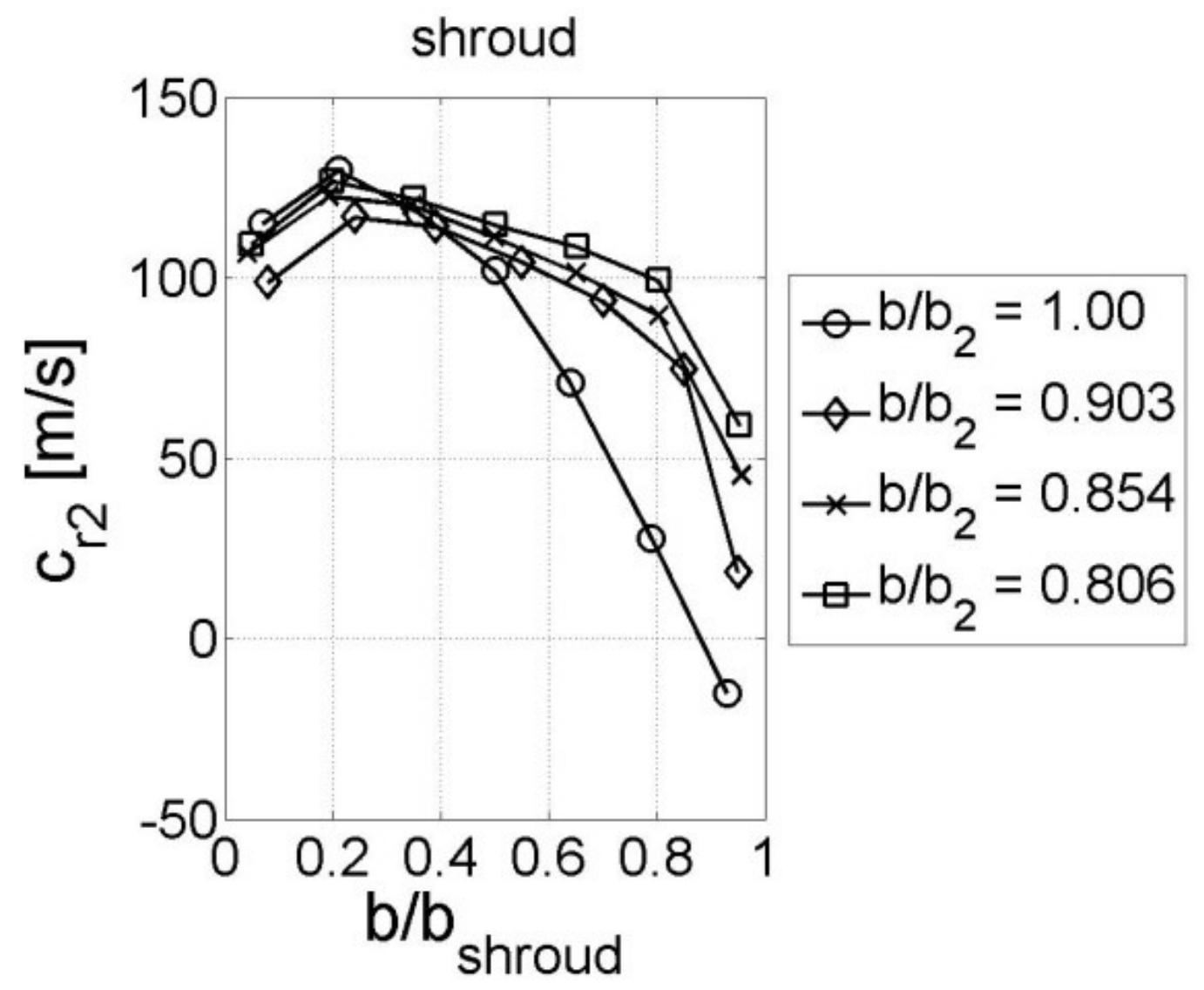

Figure 6c 


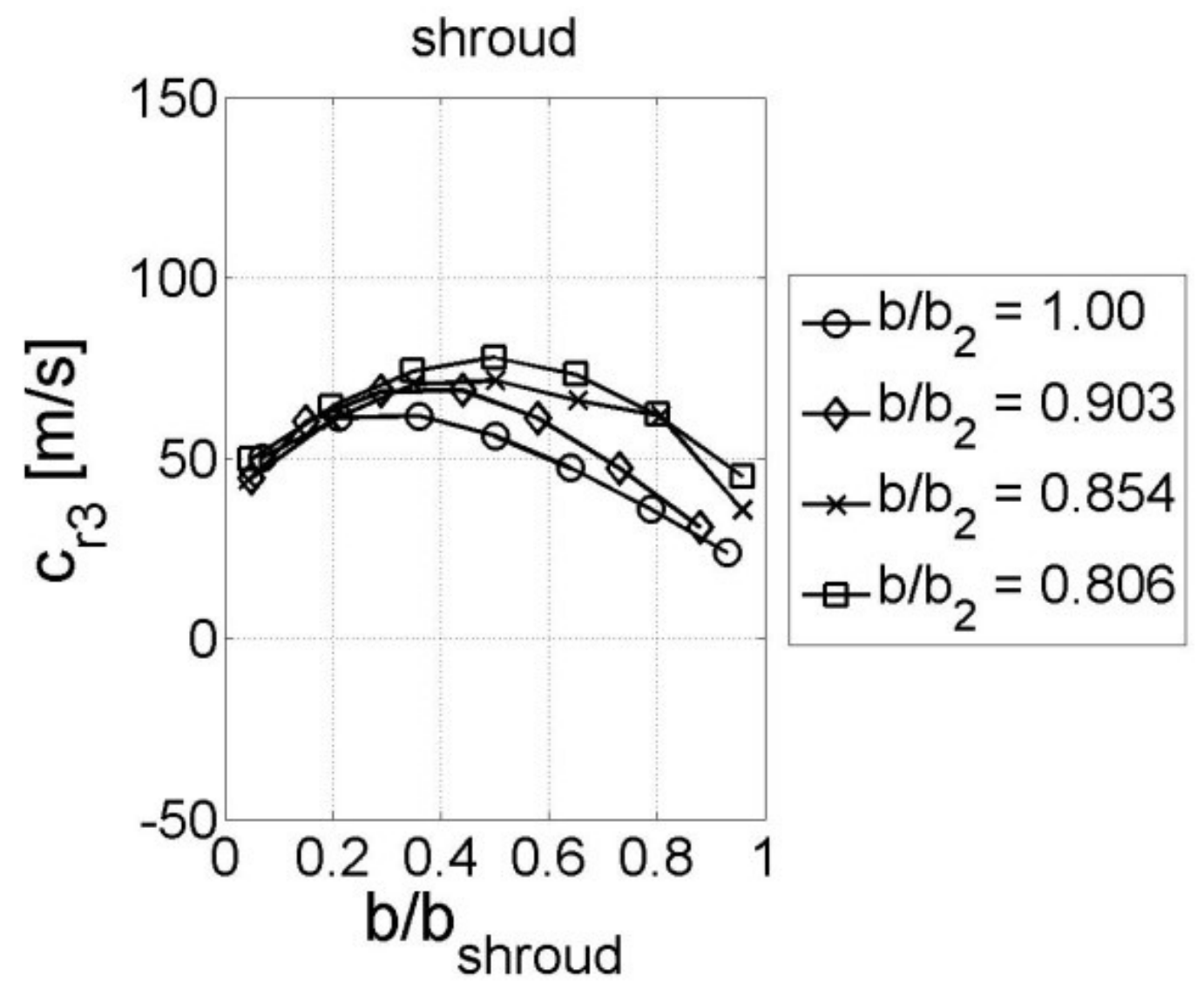

Figure 6d 


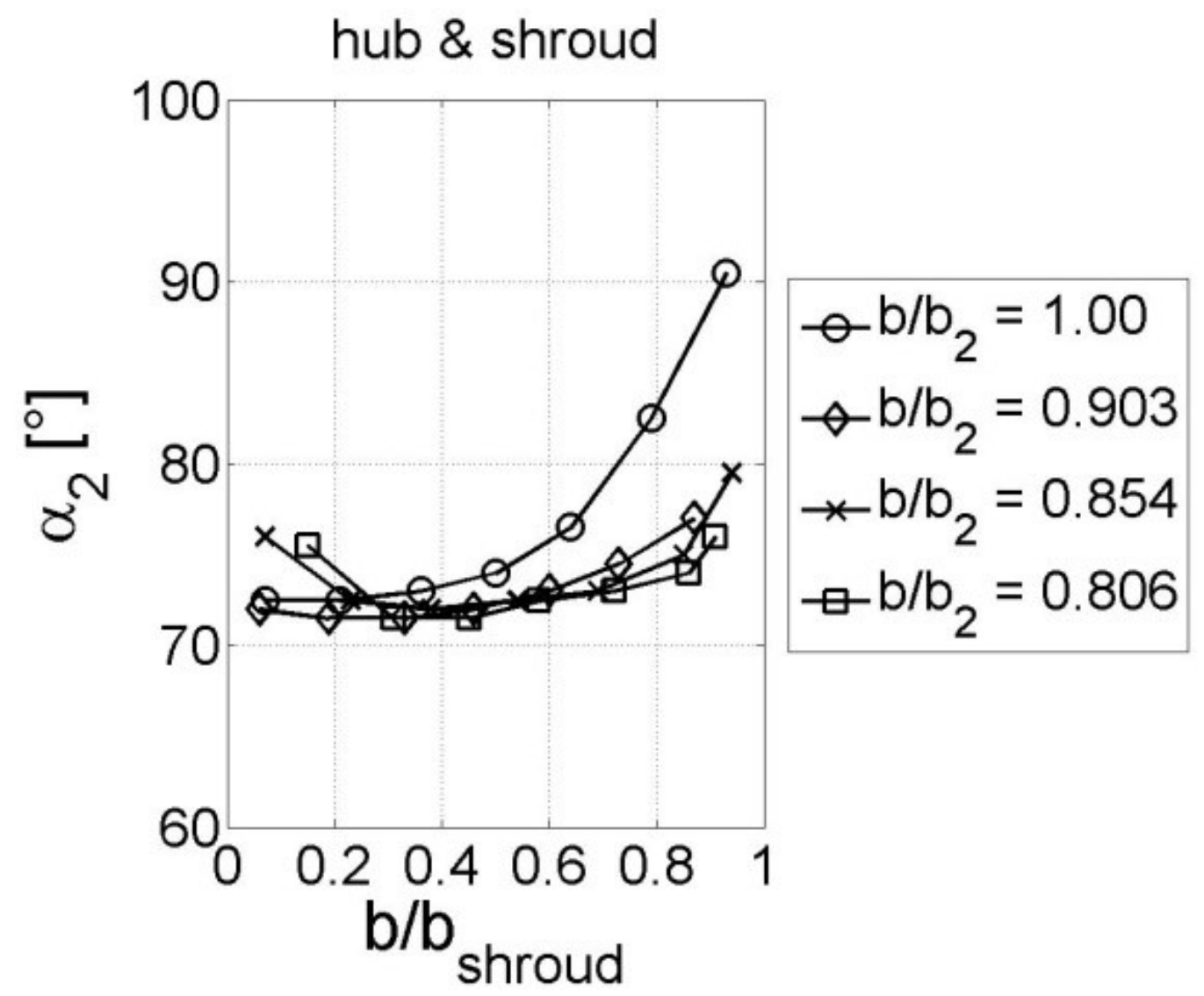

Figure 7a 


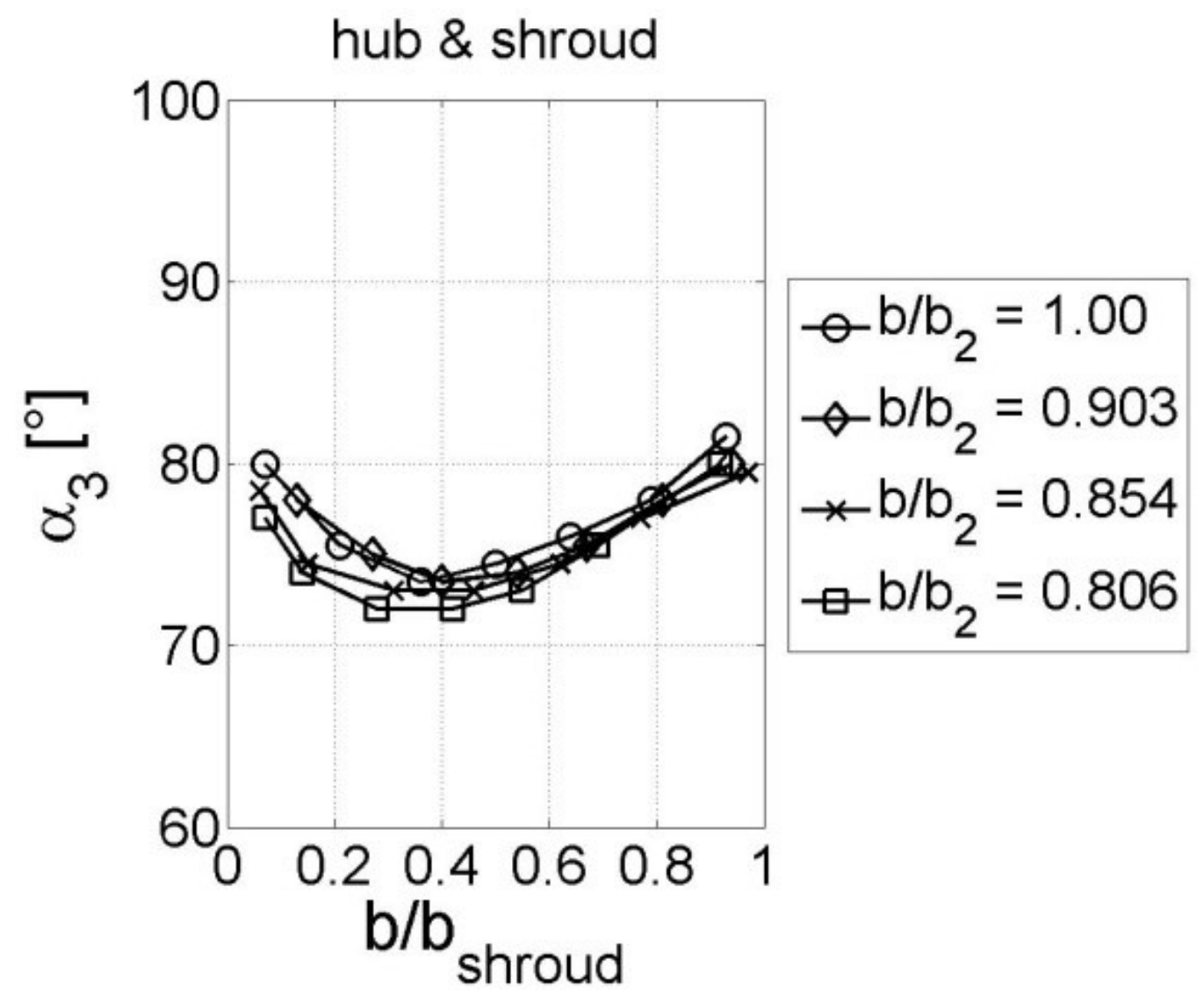

Figure 7b 


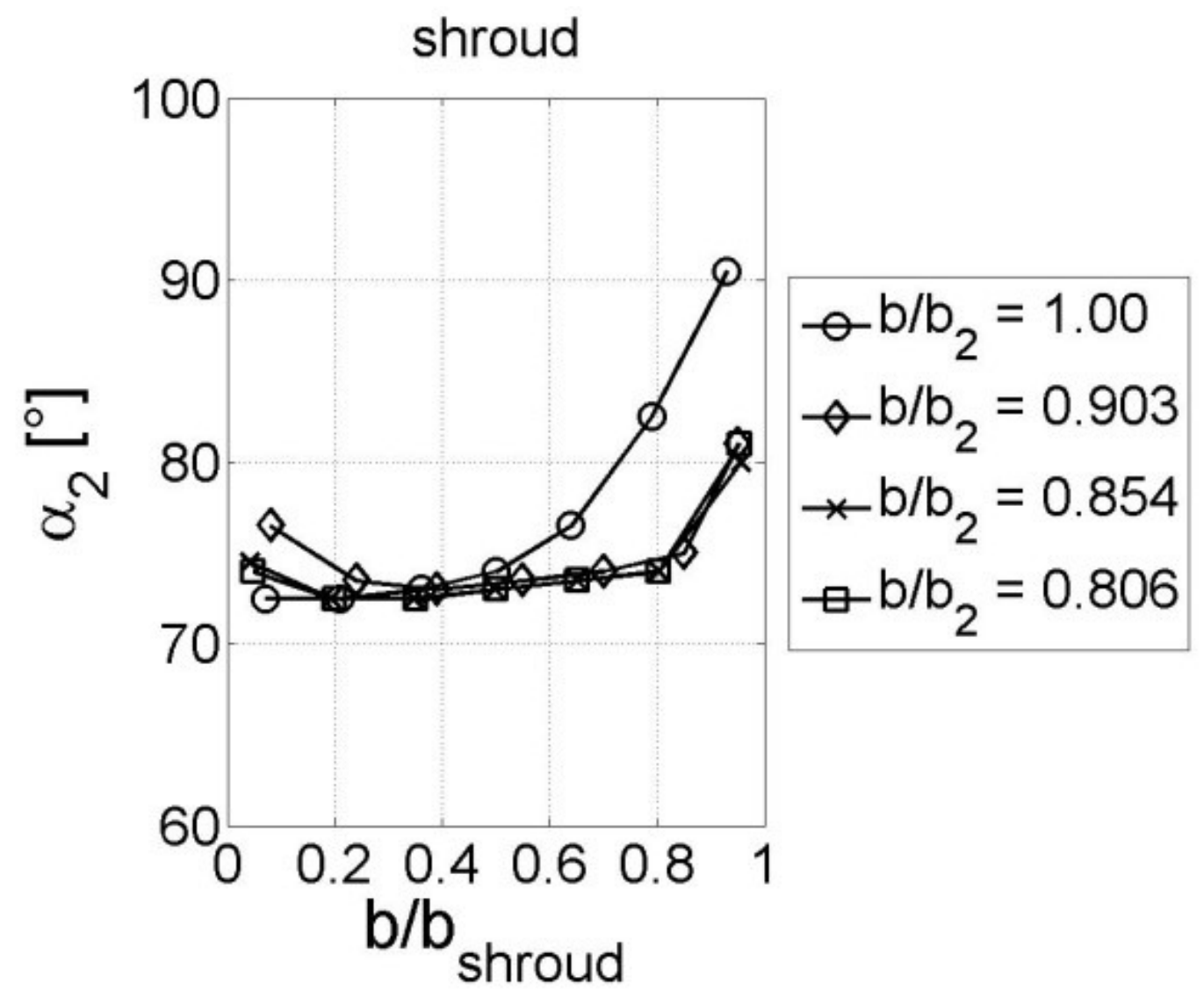

Figure 7c 


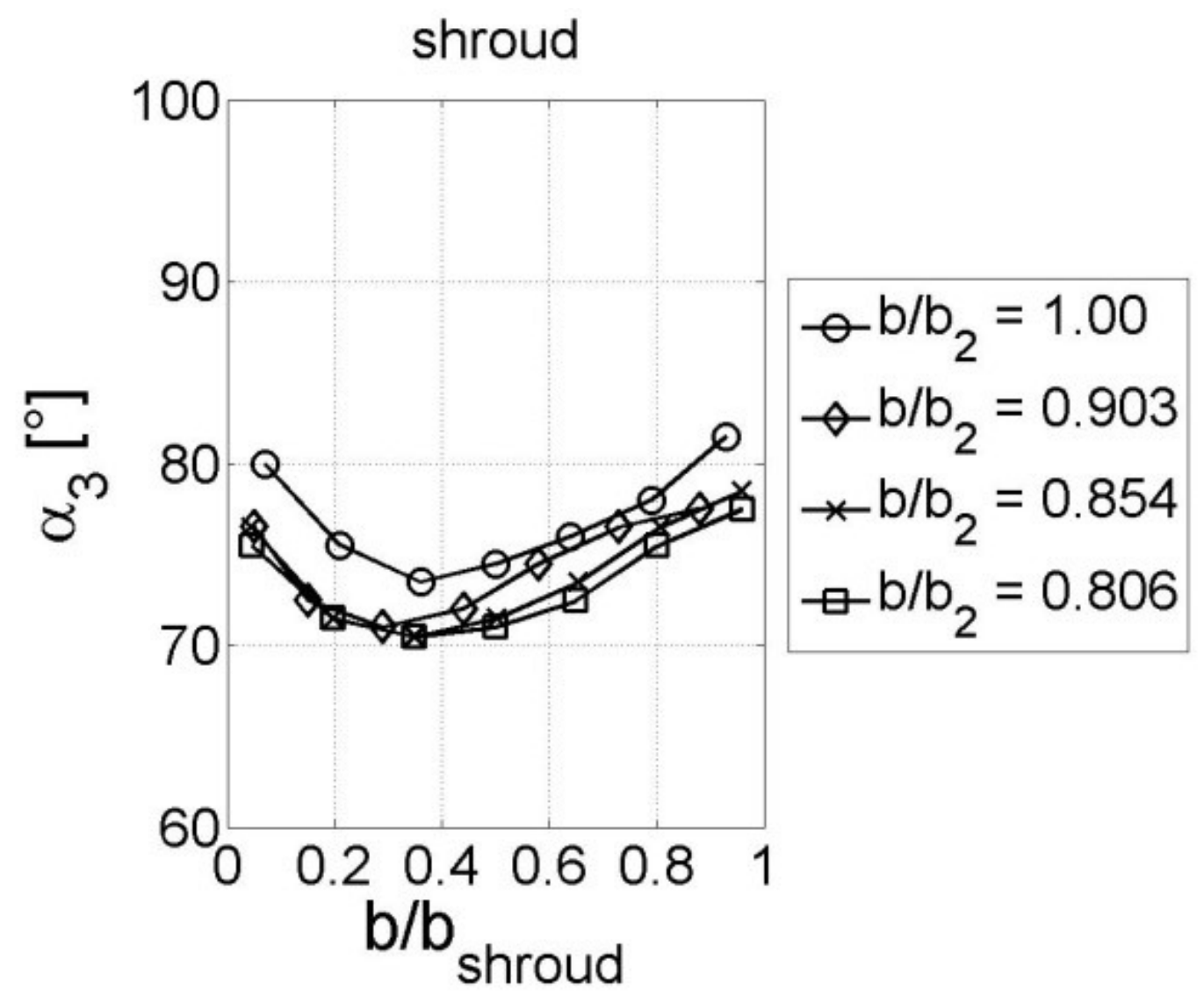

Figure 7d 


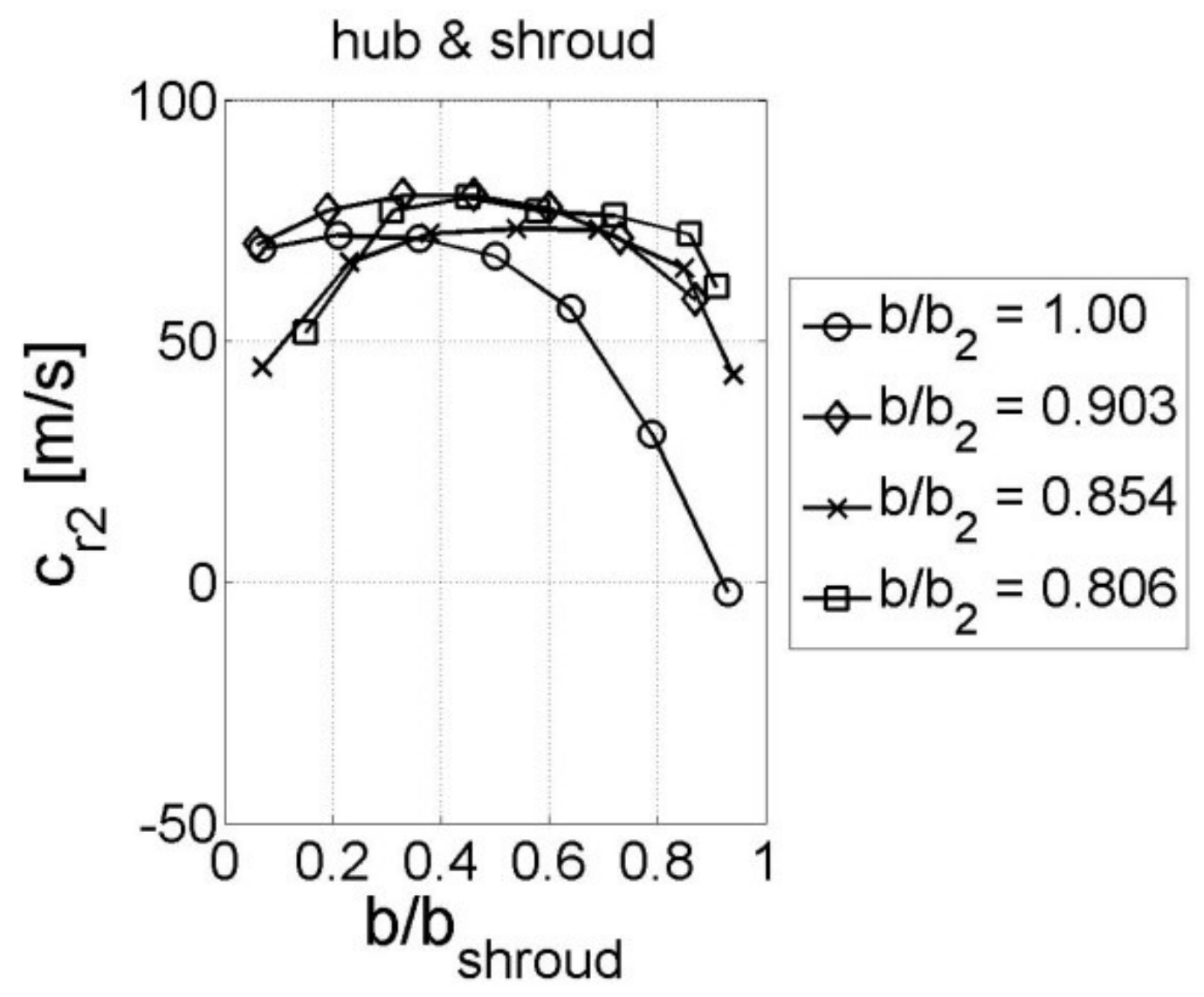

Figure 8a 


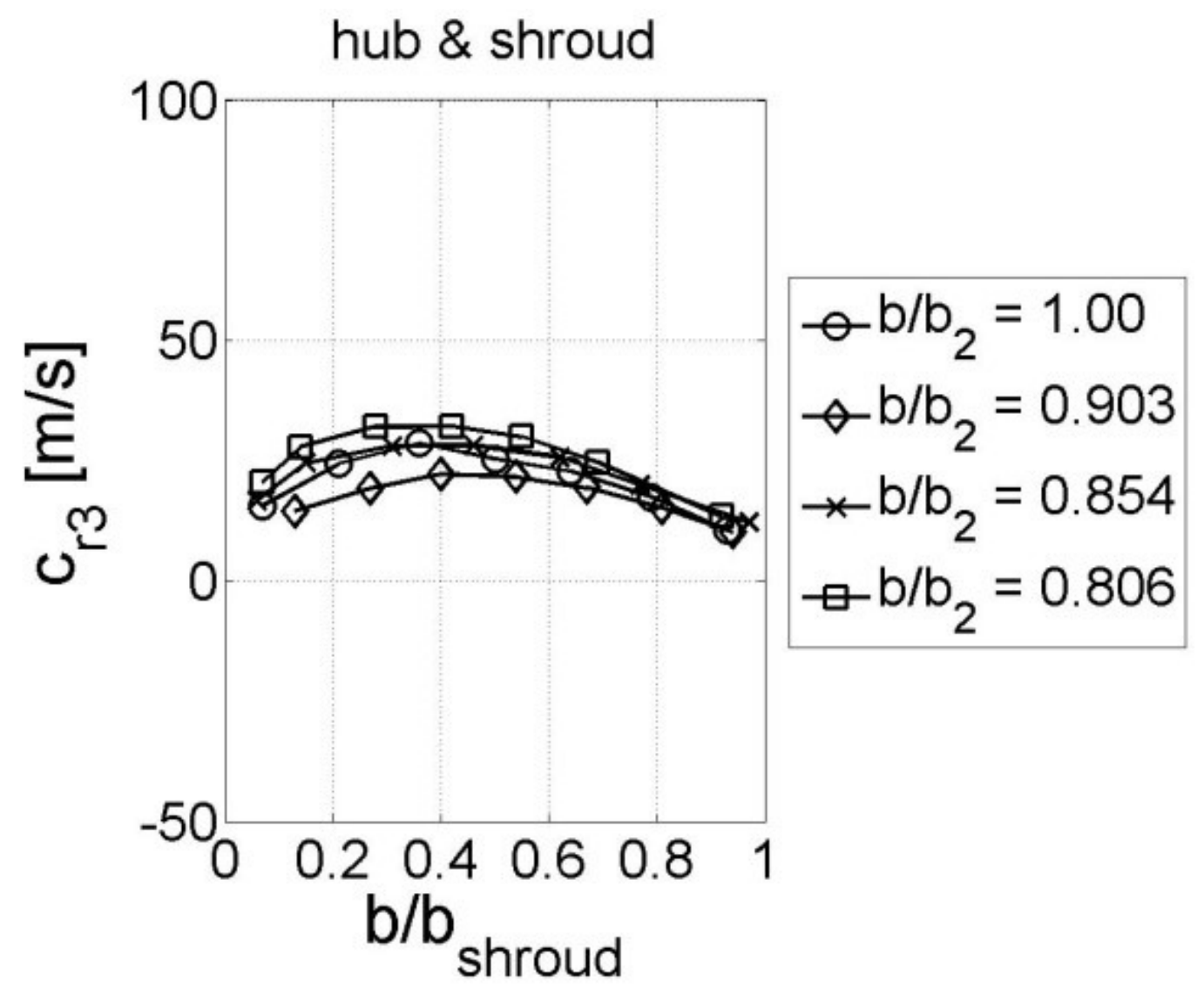

Figure 8b 


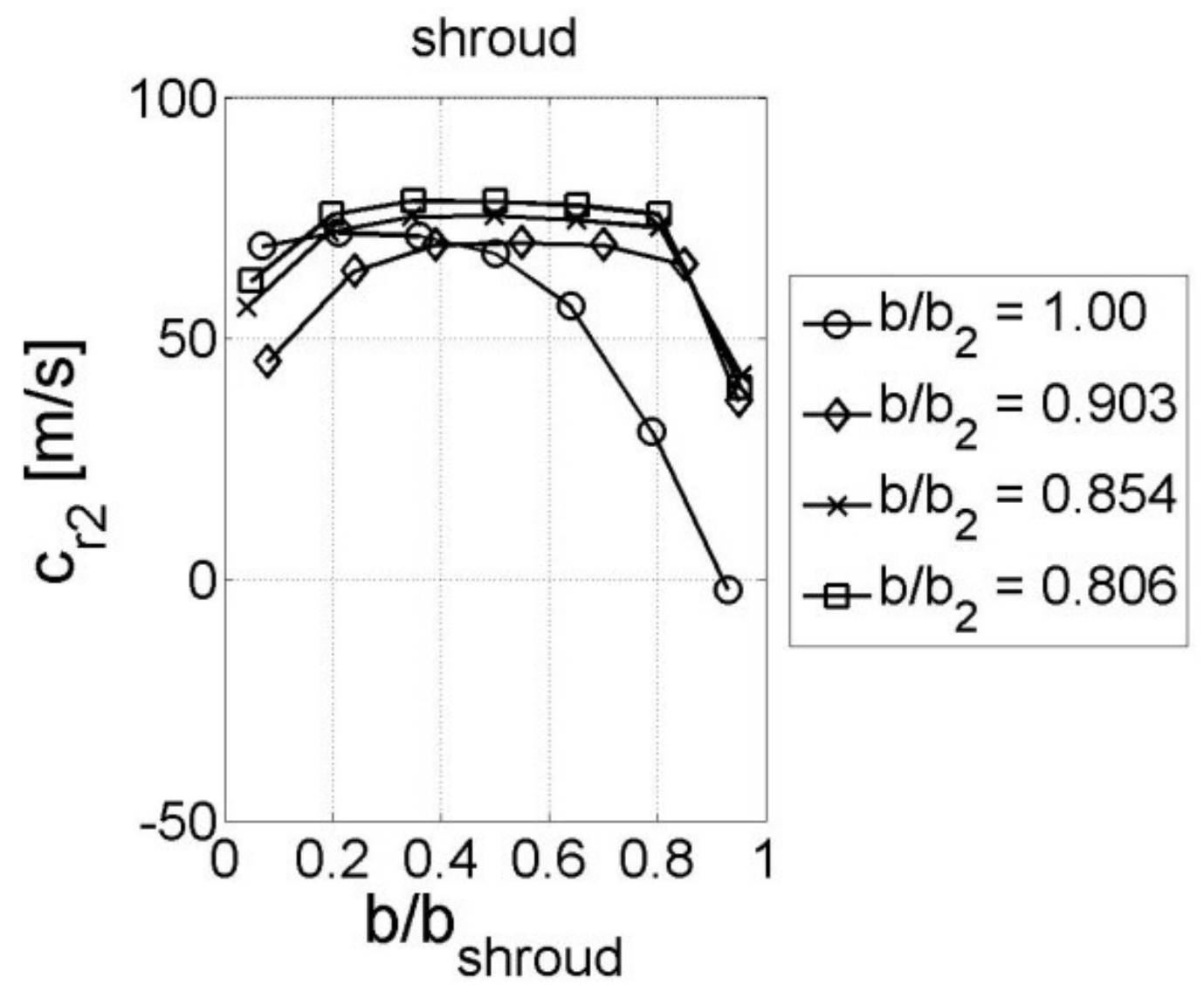

Figure 8c 


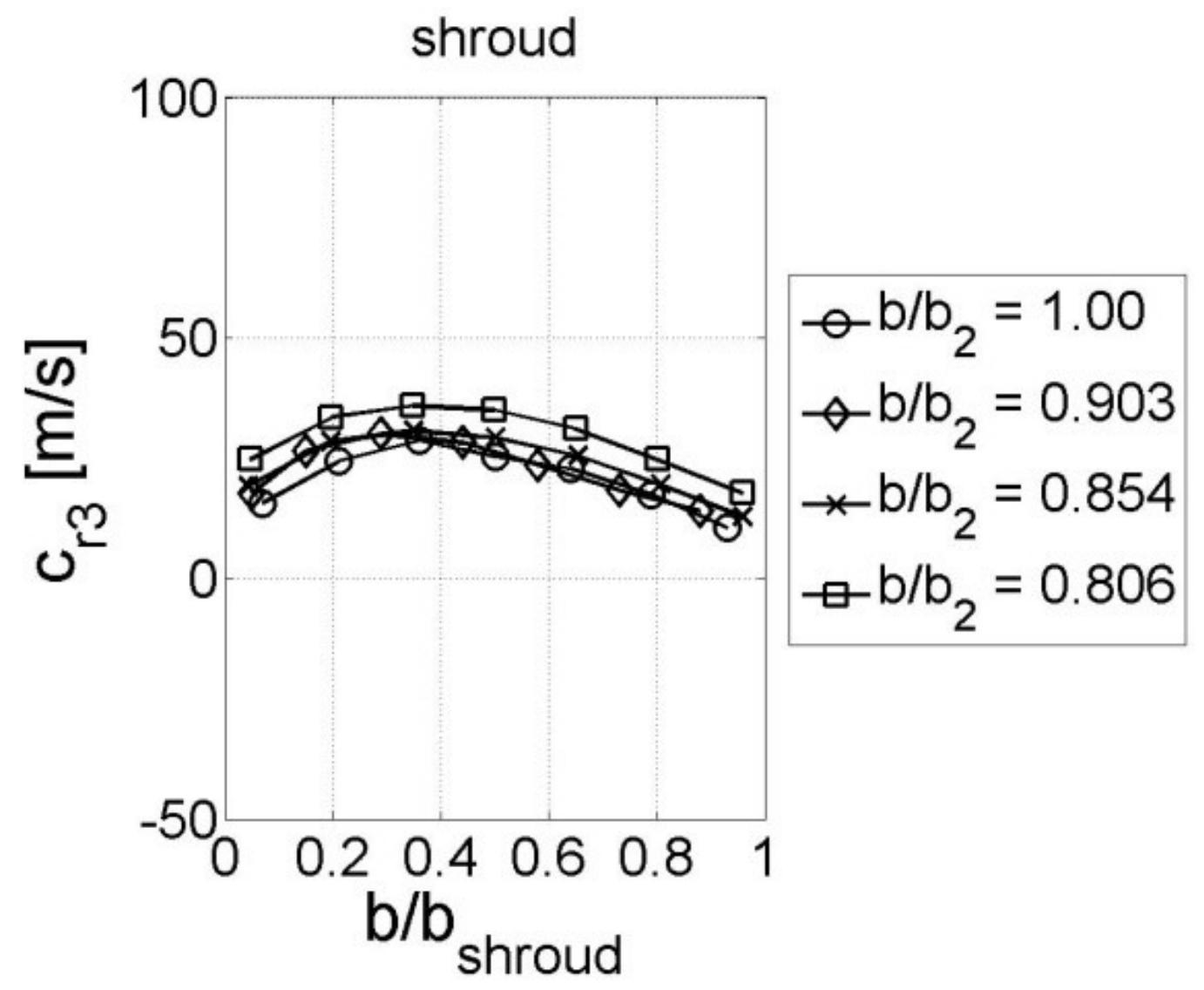

Figure 8d 


\section{Table captions:}

Table 1 The studied designs

Table 2 The maximum relative measurement uncertainties with $95.4 \%$ confidence interval

Table 3 Efficiencies at the design, high and low mass flows

Table 4 Pressure ratios at the design, high and low mass flows 
Table 1 The studied designs

\begin{tabular}{llllll}
\hline Case & $b / b_{2}$ & $b / r_{2}$ & $r_{2}, / r_{2}$ & $r_{3} / r_{2}$ & Pinch \\
\hline 1 & 1.000 & 0.1217 & 1.00 & 1.68 & Unpinched \\
2 & 0.903 & 0.1098 & 1.01 & 1.68 & Hub \& shroud \\
3 & 0.854 & 0.1039 & 1.01 & 1.68 & Hub \& shroud \\
4 & 0.806 & 0.0979 & 1.01 & 1.68 & Hub \& shroud \\
5 & 0.903 & 0.1098 & 1.01 & 1.68 & Shroud \\
6 & 0.854 & 0.1039 & 1.01 & 1.68 & Shroud \\
7 & 0.806 & 0.0979 & 1.01 & 1.68 & Shroud \\
\hline
\end{tabular}


Table 2 The maximum relative measurement uncertainties with $95.4 \%$ confidence interval

\begin{tabular}{lc}
\hline Variable & Relative measurement uncertainty \\
\hline mass flow & $\pm 0.17 \%$ \\
efficiency & $\pm 0.47 \%$ \\
pressure & $\pm 0.33 \%$ \\
flow velocity & $\pm 3.8 \%$ \\
radial velocity & $\pm 3.9 \%$ \\
flow angle & $\pm 1.0 \%$ \\
\hline
\end{tabular}


Table 3 Efficiencies at the design, high and low mass flows

\begin{tabular}{cc|cc|cc|cc}
\hline & & \multicolumn{2}{|c|}{ Design flow } & \multicolumn{2}{c|}{ High flow } & \multicolumn{2}{c}{ Low flow } \\
Case & $b / b_{2}$ & $\eta_{\mathrm{ts}, 12}$ & $\eta_{\mathrm{ts}, 13}$ & $\eta_{\mathrm{ts}, 12}$ & $\eta_{\mathrm{ts}, 13}$ & $\eta_{\mathrm{ts}, 12}$ & $\eta_{\mathrm{ts}, 13}$ \\
\hline 1 & 1.00 & 1.00 & 1.00 & 1.00 & 1.00 & 1.00 & 1.00 \\
2 & $0.903(\mathrm{hs})$ & 1.03 & 1.02 & 1.07 & 1.07 & 1.00 & 0.99 \\
3 & $0.854(\mathrm{hs})$ & 1.07 & 1.05 & 1.08 & 1.10 & 1.06 & 1.01 \\
4 & $0.806(\mathrm{hs})$ & 1.07 & 1.07 & 1.06 & 1.13 & 1.06 & 1.03 \\
5 & $0.903(\mathrm{~s})$ & 1.10 & 1.08 & 1.16 & 1.13 & 1.08 & 1.03 \\
6 & $0.854(\mathrm{~s})$ & 1.08 & 1.05 & 0.47 & 0.88 & 1.07 & 1.01 \\
7 & $0.806(\mathrm{~s})$ & 1.07 & 1.05 & 0.28 & 0.91 & 1.04 & 1.01 \\
\hline
\end{tabular}


Table 4 Pressure ratios at the design, high and low mass flows

\begin{tabular}{cc|cc|cc|cc}
\hline & & \multicolumn{2}{|c|}{ Design flow } & \multicolumn{2}{c|}{ High Flow } & \multicolumn{2}{c}{ Low Flow } \\
Case & $b / b_{2}$ & $\pi_{\mathrm{ts}, 12}$ & $\pi_{\mathrm{ts}, 13}$ & $\pi_{\mathrm{ts}, 12}$ & $\pi_{\mathrm{t}, 13}$ & $\pi_{\mathrm{ts}, 12}$ & $\pi_{\mathrm{ts}, 13}$ \\
\hline 1 & 1.00 & 1.00 & 1.00 & 1.00 & 1.00 & 1.00 & 1.00 \\
2 & $0.903(\mathrm{hs})$ & 1.04 & 1.03 & 1.03 & 1.03 & 1.02 & 1.01 \\
3 & $0.854(\mathrm{hs})$ & 1.04 & 1.04 & 1.01 & 1.01 & 1.02 & 1.02 \\
4 & $0.806(\mathrm{hs})$ & 1.04 & 1.04 & 1.01 & 1.02 & 1.02 & 1.02 \\
5 & $0.903(\mathrm{~s})$ & 1.04 & 1.04 & 1.02 & 1.03 & 1.02 & 1.02 \\
6 & $0.854(\mathrm{~s})$ & 1.05 & 1.04 & 0.88 & 0.90 & 1.02 & 1.02 \\
7 & $0.806(\mathrm{~s})$ & 1.04 & 1.04 & 0.85 & 0.91 & 1.02 & 1.02 \\
\hline
\end{tabular}

